Woods Hole Oceanographic Institution

Technical Report

March 1995

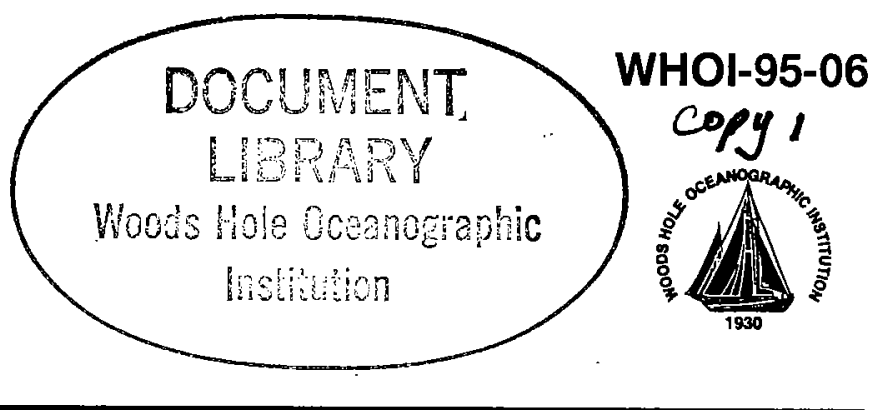

\title{
A Processing System for Argos Meteorological Data
}

\author{
by
}

Nancy R. Galbraith

$+$

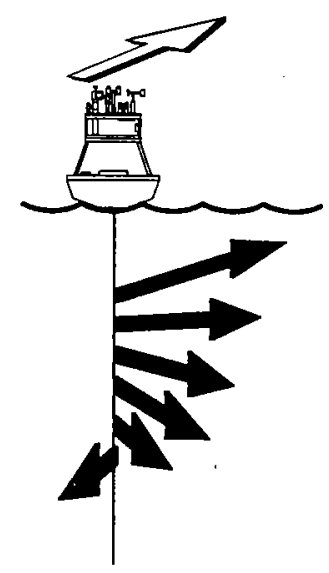


WHOI-95-06

UOP-95-03

A Processing System for Argos Meteorological Data

by

Nancy R. Galbraith

Woods Hole Oceanographic Institution

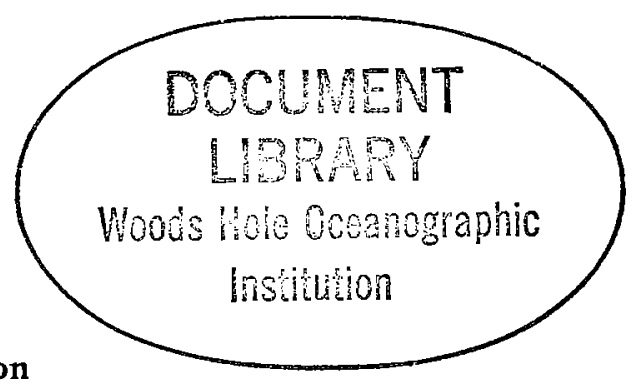

Woods Hole, Massachusetts 02543

March 1995

\section{Technical Report}

Funding was provided by the Office of Naval Research through Grant No. N00014-94-1-0161.

Reproduction in whole or in part is permitted for any purpose of the United States Government. This report should be cited as Woods Hole Oceanog. Inst. Tech. Rept., WHOI-95-06.

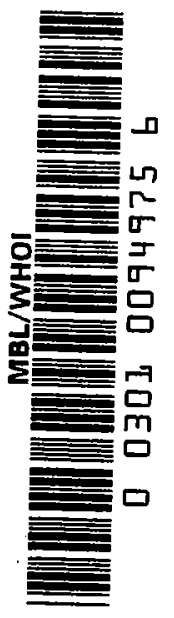

Approved for public release; distribution unlimited.

Approved for Distribution:

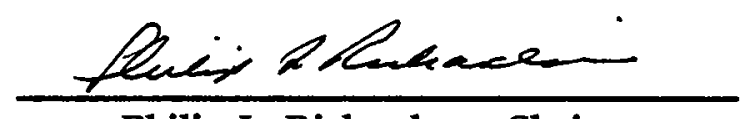

Philip L. Richardson, Chair

Department of Physical Oceanography 



\title{
A Processing System for Argos Meteorological Data
}

\author{
Nancy R. Galbraith \\ Upper Ocean Processes Group \\ Physical Oceanography Department \\ Woods Hole Oceanographic Institution
}

13 March 1995 



\section{Abstract}

Upper Ocean Processes Group meteorological data is transmitted from surface buoys via Argos satellite and processed in an automatic mode on a UNIX workstation. Data is extracted from input files based on instrument type and experiment, processed as appropriate, and plotted, without user intervention. While the processing system normally runs automatically, it is designed so that modules can also be run directly from a terminal when necessary. The Argos processing system allows us to monitor the meteorological data being collected in the field, and provides early information about problems with sensors, instruments, or buoys, when they occur. The automatic process allows more information to be viewed with less effort, and increases the usefulness of the Argos data. 



\section{Contents}

Abstract i

1 UNIX Implementation and Overview 1

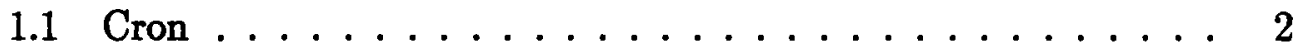

2 Main Processing Script 3

3 Processing VAWR Data 4

3.1 Shell Script gargle.sh . . . . . . . . . . . . . 5

3.2 Program Gargle ................. 5

3.3 VAWR Table Files ................ 6

4 Processing MMET Data $\quad 7$

4.1 Shell Script Imet.sh . . . . . . . . . . . . . . 8

4.2 Program Gargleimet . . . . . . . . . . . . . . 9

4.3 IMET Table Files . . . . . . . . . . . . . . . 9

$5 \quad$ Processing Engineering Variables 10

6 Processing Position Data 11

7 Data Transmission Scripts 12

8 Plotting Scripts $\quad 13$

8.1 Plot Plus Time Series Plots . . . . . . . . . . . . . . 13

8.2 Matlab Position Plot ................. 14

9 Appendices $\quad \mathbf{1 5}$

Appendix I. Startup Shell Scripts . . . . . . . . . . . . . 15

Appendix II. VAWR Processing . . . . . . . . . . . . . . 19

Appendix III. IMET Processing . . . . . . . . . . . . 25

Appendix IV. Engineering PTT Processing . . . . . . . . . 33

Appendix V. Position Processing Scripts . . . . . . . . . . . 38

Appendix VI. Data Distribution Scripts . . . . . . . . . . 41

Appendix VII. Plotting Scripts and Sample Plots . . . . . . . . 43 


\section{UNIX Implementation and Overview}

Data transmitted from surface buoys via Argos satellite for the Upper Ocean Processes (UOP) Group experiments are processed in an automatic mode on a Sun workstation, Griffon, using a series of shell scripts and C programs initiated by the UNIX cron utility. Files of data from all of the UOP's active Argos transmitters are sent daily from Service Argos' computers in Landover, Maryland, using ftp. The UNIX cron utility runs a script every hour which checks for incoming data. When a new data file is found, processing scripts are activated.

Each platform transmitter terminal, or PTT, in the field includes its own identification number in the messages it sends to Service Argos. This number allows Service Argos to route each message to the correct destination, grouping the messages it receives for retransmission to the PTT owner. Each PTT identification number is associated with an experiment number, which is used for routing and accounting purposes, and so data for each experiment is bundled into a separate file. Currently, we receive data from our Arabian Sea buoy in a file called argos.dat, and data from our GLOBEC buoy in file argos2.dat.

Incoming data is processed by a suite of $\mathrm{C}$ programs and shell scripts. While these programs and scripts are normally run automatically by the UNIX scheduler, cron, they are designed so they can also be run directly from a terminal in cases where Argos transmissions are interrupted, an instrument must be reprocessed, or non-standard plots are desired.

The primary goal of the Argos processing system is to monitor the meteorological data being collected in the field, as soon as it becomes available. The system also provides early information about problems with sensors, instruments, or buoys, when they occur. By automating the entire process, we allow more information to be viewed with less effort, and increase the usefulness of the Argos data. 


\subsection{Cron}

The UNIX cron utility is currently run by user nan on Griffon. Cron executes commands at specific times. The commands are entered into a table, called the cron table, by program crontab. The cron table entry on Griffon can be edited by its owner by typing crontab -e. New cron table entries can be started using crontab -e, or checked by typing crontab - 1 . The cron table entry for the Arabian Sea and GLOBEC Argos processing is:

$1 * * * *$ /gdata/argos/argos.sh

$18 * * 1-5 / \mathrm{puli} / \mathrm{data} / \mathrm{arab} / \mathrm{argos} / \mathrm{dopl}$.sh

$18 * * 1-5 / \mathrm{puli} /$ data/globec/argos/dopl.sh

The first entry runs the script argos.sh at one minute past every hour, every day. The second and third commands generate plots at $8 \mathrm{a.m}$. on weekdays only, using plotting scripts for two experiments in their processing directories.

The crontab entries are basically names of shell script programs. To change the processing system, the scripts themselves can be edited, without having to alter the crontab entry. As experiments start and end, the appropriate commands can be added to or deleted from the main processing scripts.

The directory /gdata/argos on Griffon contains all the shared processing software and has subdirectories for each active experiment. These experiment subdirectories contain archives of Argos data and information about the instrumentation. The processed data normally resides, along with experiment-specific scripts, on another workstation, on a disk that is mounted on Griffon using the Network File System (NFS).

If data must be retransmitted from Service Argos for any reason, argos.sh will automatically process any new data every hour. As long as Service Argos does not send more than one file within that time period, cron will cause argos.sh to copy and process all incoming data files with the names 
specified in the script. To process an incoming file immediately, the script argos.sh can be invoked from the keyboard.

\section{Main Processing Script}

The main processing is initiated by the shell script argos.sh, in Griffon's directory /gdata/argos. Incoming Argos data is written to that directory in files named argos.dat and argos2.dat, which represent two different Argos accounts. This script handles each input file separately, first processing all data in argos.dat.n, then argos2.dat.n.

For each experiment, the script first checks for the existence of the appropriate incoming data file. If the file exists, it is moved to a file named argos(2).dat.n, where $n$ is a monotonically increasing number. Note that if the file argos.dat.1 does not exist, that filename is used for the new file. If it does exist, the directory is checked by the shell script findlast.sh to determine the next sequence number for the output filename, which is numerically one greater than the highest existing number. Therefore, removing the file argos.dat.1 will cause erratic numbering, since the next file processed will be called argos.dat.1, but incoming data files will never be overwritten by the automated processing system.

Once the file archiving is done, the script processes data from the Vector-Averaging Wind Recorder (VAWR), then data from the Improved Meteorological (IMET) System, if it is being transmitted. If IMET data is not transmitted, there is normally a tensiometer reporting, and its data is processed after the VAWR data. Position data, generated by the Argos system, is processed last. Processing each of these data sets requires a separate pass through the incoming file, looking for the appropriate Argos transmitter ids. Each of these tasks is handled by an independent shell script, which can be run manually if needed.

See Appendix I for text of the shell scripts argos.sh and findlast.sh. 


\section{Processing VAWR Data}

The script argos.sh processes VAWR data using another shell script, gargle.sh, which in turn runs a $\mathrm{C}$ program to extract and scale the incoming Argos data. Shell script/gdata/argos/gargle.sh starts one of the gargle processing programs, which extract VAWR data from a specified Argos input file based on information in a calibration file.

The VAWR data files produced by this system contain the variables yearday, wind east, wind north; wind speed, wind direction; short wave radiation, relative humidity, barometric pressure, sea temperature, air temperature, long wave thermopile voltage, body temperature, dome temperature, and long wave radiation. Air and sea temperatures are recorded in degrees centigrade, while body and dome are Kelvin temperatures. Wind vectors are recorded in meters per second, radiation values in watts per square meter, and thermopile voltage in microvolts. Relative humidity is reported as a percentage, and barometric pressure is

reported in millibars. A sample output file is contained in Appendix II.

This system uniformly uses the convention that yearday 1 begins at midnight on January 1. This is consistent with the UNIX date utility, which is used to check for invalid dates and to set date limits for plots.

Occasionally VAWR data will need to be reprocessed. This will usually occur when corrections need to be made to a table file. If a VAWR's interval counter resets, the date calculated by the software system will be incorrect, and the data will need to be reprocessed after a table file change has been made. To reprocess VAWR data in case of errors or resets, remove any unwanted or incorrect data from the file /gdata/argos/exper/vawrnnnn.arch, which is appended by the processing system. Then cd to /gdata/argos and type

gargle.sh garglenew argos.dat.nn exper vawrnnnn $\gg$

/gdata/argos/vawrnnnn. $\log 2>\& 1$ 
where $\mathrm{nn}$ is the number of the argos.dat file to be reprocessed, exper is the experiment name and nnnn is the 4-digit VAWR number. The experiment name must correspond to two data directories, one in /puli/data and one in /gdata/argos. The first, /puli/data/exper, must have a subdirectory named argos, and the second, /gdata/argos/exper, must contain a table file for the VAWR to be processed.

Note that the working data file in the processing subdirectory on Puli is overwritten daily by the automated processing system, so any changes made there will be lost. To permanently alter the working data file, the archive version of the file, in the /gdata/argos directory, must be modified.

\subsection{Shell Script gargle.sh}

Arguments to gargle.sh are the gargle program name, the input data file to be processed, the experiment, and the VAWR name. Using these arguments, gargle.sh generates filenames and commands to process the incoming data.

Gargle.sh calls program gargle or garglenew with the filenames of the input Argos file, the VAWR table file and the output VAWR data file. Then gargle.sh sorts the new data and appends it to an archive file in the experiment subdirectory on Griffon. The archive file is then sorted by date with the UNIX sort utility, deleting duplicate entries. The sorted version of the file is placed in the processing directory for the experiment on Puli, in a file names vawrnnnn.asc.

See Appendix II for text of gargle.sh.

\subsection{Program Gargle}

Program gargle extracts VAWR data from a specified Argos input file based on information in a calibration file, also called a table file. The table file 
contains the key to variable positions within the incoming records, allowing data to be extracted, and contains calibration values to be used in scaling the data. Program gargle writes data to a new file, and will overwrite an existing file if one is specified as the output file.

Gargle was adapted by Roger Goldsmith, of WHOI's Computer and Information Services (CIS) group.The original version, called gargoyle, was written by Thomas Danforth to run under the SCO Zenix operating system on a $386 \mathrm{PC}$, and was designed to work with a commercial database. Program gargle, which runs under SunOS UNIX, uses portable ASCII data files. The specifics of program gargle are beyond the scope of this manual.

There are at present two versions of the gargle program. Programs gargle and garglenew are identical except for the handling of long wave radiation. Both versions calculate long wave from independently scaled thermopile voltage and body and dome temperatures, but garglenew uses a new algorithm. Because the new type of calibration constants were not available for the Arabian Sea VAWR, we retained the original code for the duration of that experiment. The old version will be removed after the first Arabian Sea mooring is recovered.

\subsection{VAWR Table Files}

Program gargle uses table files which have the same format as those used by the tape processing programs vawr_cdf and vawr_cal, but with several extensions needed to decode the Argos record. The table files control the processing of the incoming record and provide documentation of calibrations used. The use of table files provides some flexibility to the system, accommodating changes in the incoming record.

Gargle extracts the PTT numbers from the specified table file, and uses those numbers to decide which records to extract from the incoming Argos file. It also uses the position of a variable description in the table file and the length in bits specified to determine the position and length of the variable within the Argos record. The calibration values are used by gargle 
to scale the raw data values, using the same algorithms as those used by the tape processing system. The minimum and maximum values for each variable specified in the table file prevent wild values from entering the data stream. This windowing can mask problems with sensors, and must be used very carefully, especially during instrument evaluation.

Comment lines in table files are denoted with a two-part forward arrow, consisting of a dash and a greater-than symbol. Variable identification lines begin with a number sign, an integer representing the variable position, a colon, and the short and long version of the name of the variable. A variable's short name is used to select the processing function to be used on the data in the field defined by the entry, and should not be modified.

See Appendix II for a sample VAWR table file.

\section{Processing IMET Data}

The IMET system in the GLOBEC experiment transmits hourly averages to Argos. Script argos.sh processes the IMET data, as it does for the VAWR data, by invoking a secondary shell script which in turn calls a $\mathrm{C}$ program. The shell script imet.sh calls program gargle imet, which extracts data from the incoming file using information from a table file.

The IMET system software has the capability to handle many variables, some of which have not been implemented in the IMET hardware at this time. The program which decodes the input file produces an intermediate file, which is modified by the awk script imet.awk before being archived and used. In the awk script, the variable order is changed to more closely resemble the order of variables in VAWR files. The final output file has a format which is similar to the VAWR files, but has several dummy variables, which are set to 0 .

The variables in the working or archive version of the IMET files are real yearday, wind east, wind north, dummy, dummy, short wave radiation, 
relative humidity, barometric pressure, air temperature, sea temperature, dummy, dummy, dummy, long wave radiation, battery voltage, mooring tension, and precipitation. The units for variables which are reported by both VAWR and IMET are described above. In addition, the IMET battery voltage is recorded in amps, the mooring tension in pounds, and the precipitation sensor measures cumulative precipitation in millimeters. A sample output file is found in Appendix III.

To reprocess IMET data in case of errors, use a text editor to remove unwanted data from file imet1.arch in the experiment subdirectory in /gdata/argos. This file is appended by script imet.sh. After any unwanted or erroneous data has been removed, cd to /gdata/argos and type

imet.sh argos2.dat.nn exper instrument

where $\mathrm{nn}$ is the number of the argos2.dat file to be reprocessed, exper is the experiment name, and instrument is the instrument name, normally imet1 or imet2. The experiment name must correspond to two data directories, one in /puli/data and one in /gdata/argos. The first, /puli/data/exper, must have a subdirectory named argos, and the second, /gdata/argos/exper, must contain a table file with the name of the instrument and the filename extension .tbl. Note that changes to the working data file in the experiment directory on Puli will be overwritten by the automated processing.

\subsection{Shell Script Imet.sh}

Arguments to imet.sh are the input filename, the experiment/directory, and the instrument name. Shell script imet.sh invokes program gargle imet with the name of the Argos input file, the table file and the output file. The script runs the gargle output through an awk script to compute real yearday, reorder the variables and remove data with invalid dates. The awk script also adjusts the time of the data records to the half hour by adding 
30 minutes to the reported time, and normalizes air temperatures if needed. The shell script then sorts the modified data, appends it to the archive file, sorts the archive file and copies it to the experiment's processing subdirectory in /puli/data.

See Appendix III for text of imet.sh and imet.awk.

\subsection{Program Gargle_imet}

Gargle_imet extracts the PTT numbers from the specified table file, and retrieves records with matching PTT numbers from the Argos file. The input records are decoded based on the length and position of each variable specified in the IMET table file. Data is converted from ASCII hexadecimal to floating point and written out in comma-separated ASCII strings. Output is to a new file, and, if an existing file is specified, it will be overwritten.

The variables output by program gargle imet in the present implementation are: Integer day, hour, barometric pressure, air temperature, sea temperature, wind east, wind north, relative humidity, short wave radiation, long wave radiation, precipitation, battery voltage, and mooring tension. The order of these variables is modified by the shell script imet.sh, as described above.

\subsection{IMET Table Files}

The IMET table files are similar to the VAWR table files used by program gargle. Because IMET sensors return calibrated data in scientific units, the IMET table files do not contain calibration coefficients for most variables. They do contain information needed to decode and scale the incoming data and to control the processing itself.

At present, each Argos IMET record contains two IMET data records. To 
accommodate that double record in one pasis by program gargle_imet, the table file essentially contains two complete, identical descriptions of the IMET record. See Appendix III for a sample of an IMET table file.

\section{$5 \quad$ Processing Engineering Variables}

For some experiments, a separate Argos transmitter reports mooring tension from an independent tensiometer. Other variables, of interest for engineering purposes, may be included in the Argos record for these transmitters. For the Arabian Sea I experiment, variables transmitted are tension and battery voltage.

Shell script dotens.sh in directory /puli/data/arab/argos processes the data from the engineering Argos transmitter. This script is normally called with the number of the argos.dat.n file to be processed. If it is called with no arguments, it will process the most recent argos.dat.n file in directory /gdata/argos.

Dotens.sh uses the awk script tens.awk to identify tensiometer records in the incoming Argos file and to calculate year day. These fields are written to file tens.raw. Tension and battery voltage are ASCII hexadecimal fields, and are converted to decimal values and scaled in program conv. Conv writes the working tension file, tens.asc, which contains real yearday, year, month, day, hour, minute, second, tension, dummy, and battery voltage.

To reprocess tension data in case of errors, go to the processing directory for the experiment, usually on Puli. If necessary, remove any incorrect data from the database by editing file tens.raw, which is appended by this script, then type

dotens.sh nn

where $\mathrm{nn}$ is the number of the argos.dat file you wish to reprocess. 
See Appendix IV for the text of dotens.sh, tens.awk, and conv.c.

\section{Processing Position Data}

Position data is processed by a separate script, and stored in a subdirectory under the usual processing directory for Argos data for each experiment. The script that processes Arabian Sea I position data, for example, is doposit.sh, and is found in /puli/data/arab in the argos/posit subdirectory. Position data is generated by Service Argos and incorporated into the incoming VAWR and IMET records.

Unlike meteorological data, position data seldom needs to be reprocessed, as it is not liable to contain timing errors and is not subject to calibration. However, it is often desirable to remove portions of the position record for an experiment, such as the steaming time before a mooring deployment. This allows plotting with auto-ranging axis limits, at an expanded scale, so that movement of a mooring can be monitored easily.

Argos position records contain a value indicating the quality of the calculated position, a number between one and three, with three as the highest quality. In this processing scheme, all location records are used, but the quality word is retained for future use. Including all position values, the Argos positions seem to be accurate to approximately one kilometer.

To reprocess position data, use a text editor to remove unwanted values, if necessary, from archive files in /puli/data/exper/argos. For GLOBEC, which generates position records for both IMET and VAWR PTTs, these files are in /puli/data/globec/argos/posit and are named vlpos.arch.asc and ilpos.arch.asc. For the Arabian Sea deployment, which receives only VAWR positions, the position file is pripos.arch.asc. After removing any incorrect data, cd to /puli/data/exper/argos/posit and reprocess by typing

doposit.sh nn 
where $\mathrm{nn}$ is the number of the argos(2).dat file you wish to rerun. If this argument is omitted, doposit will process the most recent Argos file for the experiment related to the current working directory.

Position data is extracted from the Argos file by finding records in the file with a line length of 13 words and piping those records to an awk script, posit.awk. That script calculates real yearday, normalizes longitude to 180 degrees, and writes out PTT number, year, month, day, hour, minute, second, yearday, lat, long and a quality flag. This data is written to the temporary file junk.dat. The shell script then checks this file for the desired PTT numbers, and if any exist, appends the position record, stripped of the PTT number, to the appropriate archive file. This file is then sorted and the output written over the working version of the position file. For the Arabian Sea experiment, that file is /puli/data/arab/argos/posit/arab1.pos.

See Appendix V for the text of doposit.sh and posit.awk.

\section{Data Transmission Scripts}

To automatically distribute data to hosts with anonymous ftp accounts, ftp is run from the shell script ftp.sh, invoked by argos.sh. The script uses the -n and -i flags, which allow non-interactive use of ftp, redirecting input commands from the text of the script itself. For sites receiving data via ftp, we transmit the entire working version of the data every day, overwriting the data previously sent.

For hosts without anonymous ftp sites, we use the UNIX mail utility to distribute the data. When using mail, we send only updates to the data. Since we want to be sure to send a full day's worth of data, we use the UNIX utility tail to extract the last 100 records from the working version of the data files. In the current implementation, we extract variables of interest for our mail recipients, using an awk script, x.awk. We prepend a header record identifying the data as ours, and a record containing the variable names, before invoking mail. 
See Appendix VI for the text of the scripts used to distribute Argos data. Note that the hosts names and IP addresses have been changed in the scripts reproduced there, for security purposes. These scripts can be run manually to retransmit data if necessary.

\section{Plotting Scripts}

Plots of all incoming data are generated and printed automatically on weekday mornings. The plotting scripts, which can be different for each experiment, are found with the processed data in the experiment subdirectories, currently on the workstation Puli. The program Plot Plus, written by Donald Denbo of NOAA's Pacific Marine Environmental Laboratory, is used to create multi-panel plots of instrument data. Maps of mooring locations are created using Matlab, a commercial numerical software package.

Plots of Argos data are used to monitor both meteorology and instrumentation, so we display the variables of meteorological interest on a separate plot from those of engineering interest. The scripts that create these plots are described here, see Appendix VII for examples.

\subsection{Plot Plus Time Series Plots}

\subsubsection{Scientific Variables Plot}

The command file argoss.ppc is used with program pplus to plot VAWR Argos meteorological data. The arguments are start day, end day, and input filename. The automated processing system invokes this script with a 3-day time span ending on the current day provided by the UNIX date utility.

See Appendix VII.2 for the text of the script argoss.ppc and a sample output plot. 


\subsubsection{Engineering Variables Plot}

The pplus command file argose.ppc plots the variables that are of interest primarily for engineering purposes. Some of these variables are reported by the VAWR, some by the IMET or the tension recorder, depending on the Argos configuration for each experiment. The arguments are identical to the arguments for argoss.ppc, above. See Appendix VII.3 for the text of argose.ppc and a sample output plot.

\subsection{Matlab Position Plot}

Matlab script posit1.m is used to plot Argos positions. Because it is essential to see the most recent position value, we allow the plot to self-scale. This assures that any change in position will be very visible on the final plot, not cropped because it is out-of-bounds.

For some experiments, a watch circle is overplotted on the positions. This indicates the calculated limits of the mooring line, and is based on the depth of the mooring. Care must be used when plotting watch circles, however, since the accuracy of the Argos position information is only about one kilometer. For deep-water moorings, like the Arabian Sea, this is sufficient for the large watch circle of over $3 \mathrm{~km}$. For a shallow mooring like GLOBEC, with its watch circle of about 40 meters, the Argos error exceeds the expected watch circle, so the watch circle is not plotted.

See Appendix VII.4 for the text of the Matlab position script, and sample output plots. 


\section{Appendices}

Appendix I. Startup Shell Scripts

Appendix I.1. Shell Script argos.sh

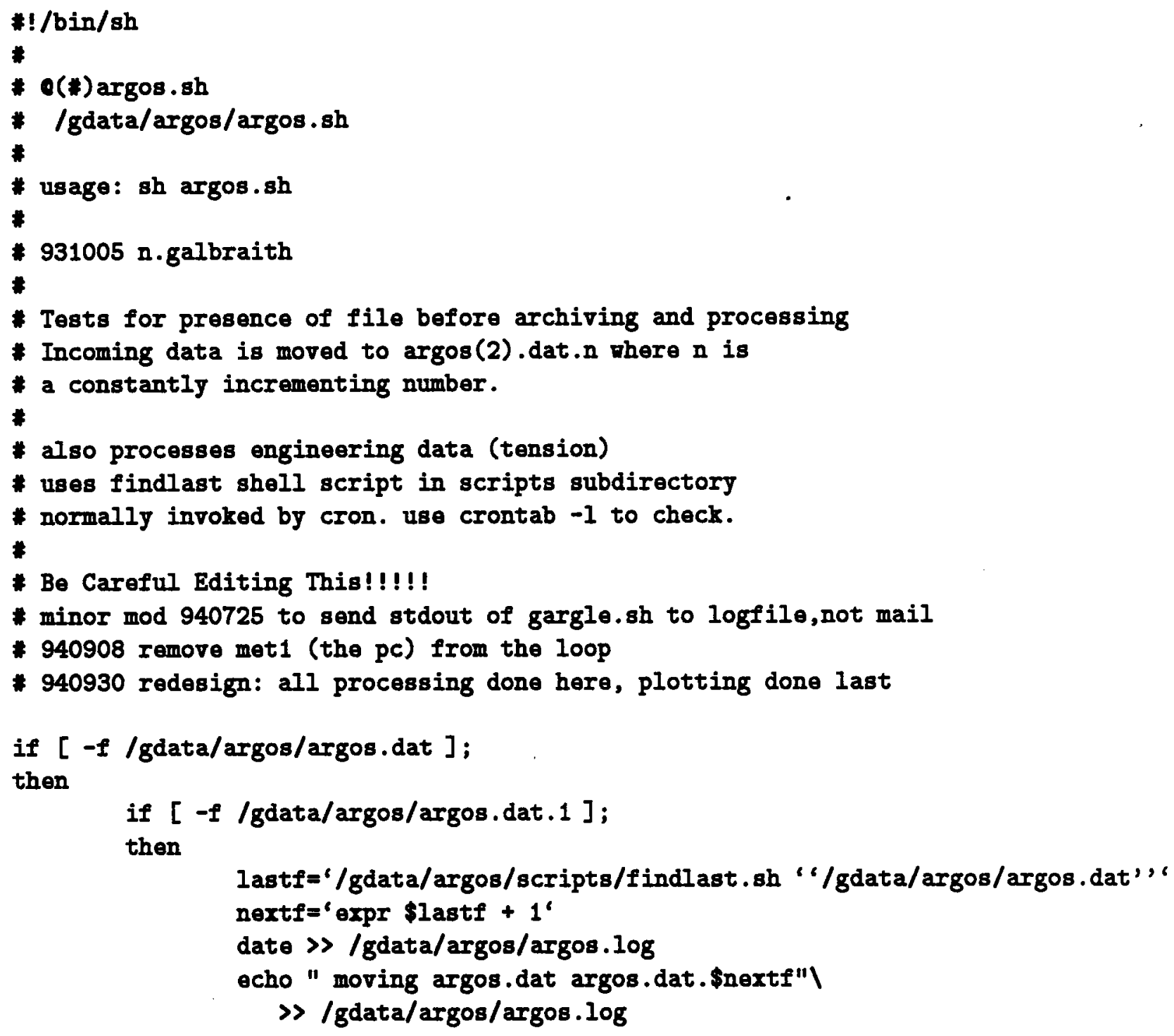




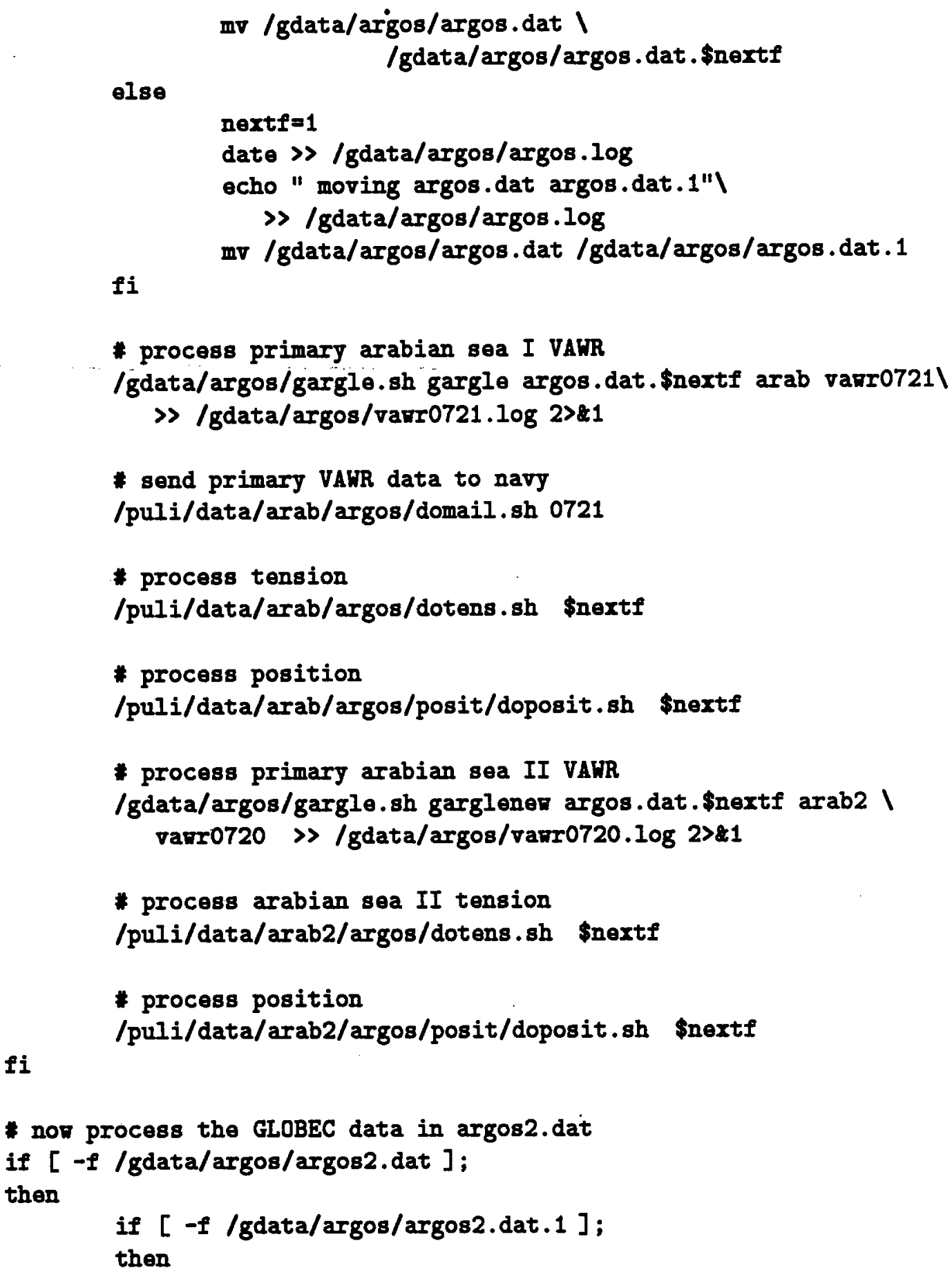




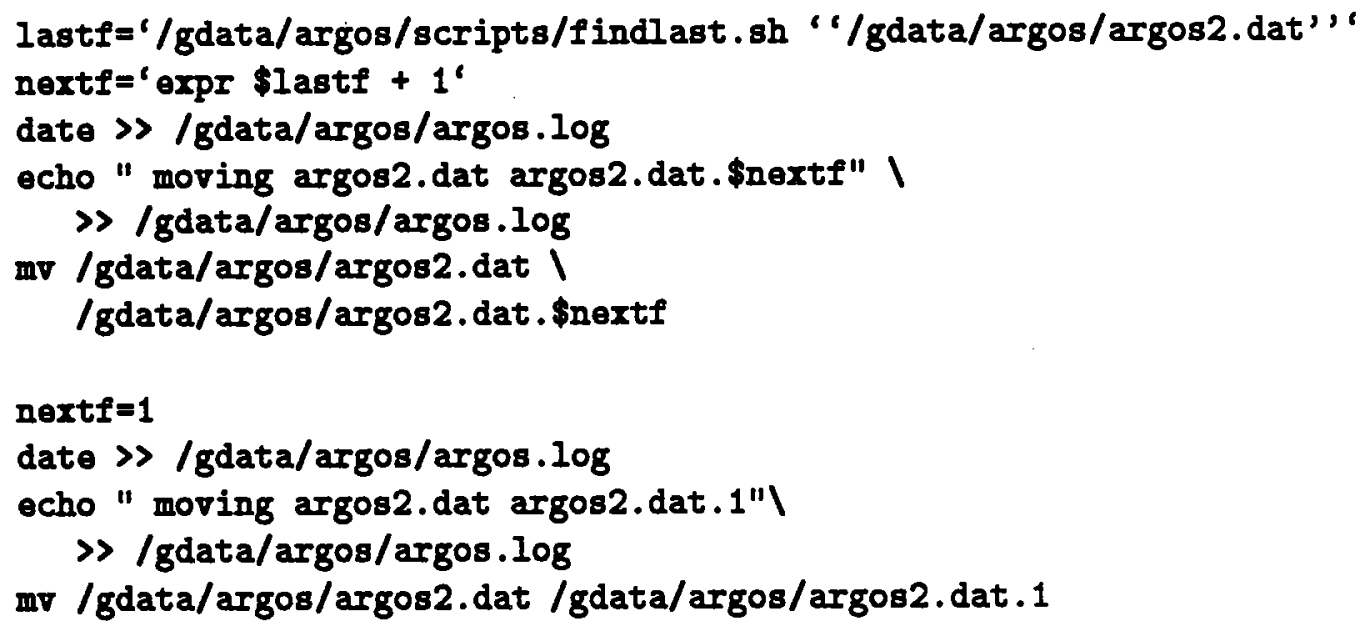

* process GLOBEC primary VATR from file argos2.dat.n /gdata/argos/gargle.sh garglener argos2.dat.\$nextf ।

globec varr0707 \/gdata/argos/vanr0707.log 2>\&1

* process GLOBEC primary IMET - includes tension

/gdata/argos/imet.sh argos2.dat.\$nextf globec imet1 I

\/gdata/argos/globecimet1.log 2>\&1

* process GLOBEC secondary VAWR

/gdata/argos/gargle.sh. garglenen argos2. dat.\$nextf ।

globec vanr0380 \/gdata/argos/varr0380.log 2>\&1

* process GLOBEC secondary IMET

/gdata/argos/imet.sh argos2.dat.\$nextf globec imet2 I

〉/gdata/argos/globecimet2.log 2>\&1

* send GLOBEC data to recipients

/gdata/argos/globec/ftp.sh 〉./gdata/argos/globec/ftp.log 2>\&1

* process position

/puli/data/globec/argos/posit/doposit.sh \$nextf

fi 


\section{Appendix I.2. Shell Script Findlast.sh}

This script works with groups of files with three-part names, where the parts of the names are separated by periods, and the third part of the name is a version number. It will find the file with name matching the two parts specified in argument 1 with the highest version number on disk. Findlast is called by argos.sh and doposit.sh, but it can also be invoked from the keyboard to determine the number of the most recent argos.dat or argos2.dat file. It returns only the number of the file, not the complete filename.

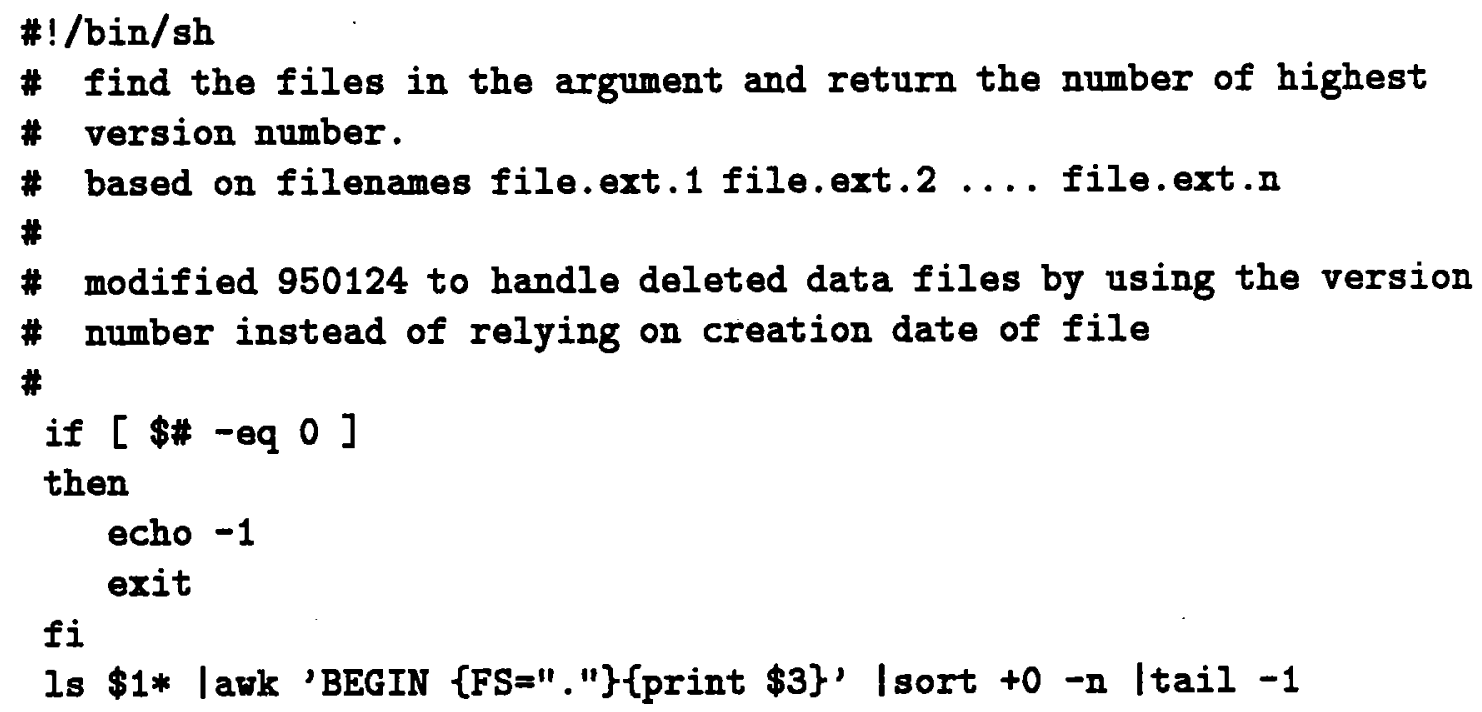


Appendix II. VAWR Processing

Appendix II.1. Shell Script gargle.sh

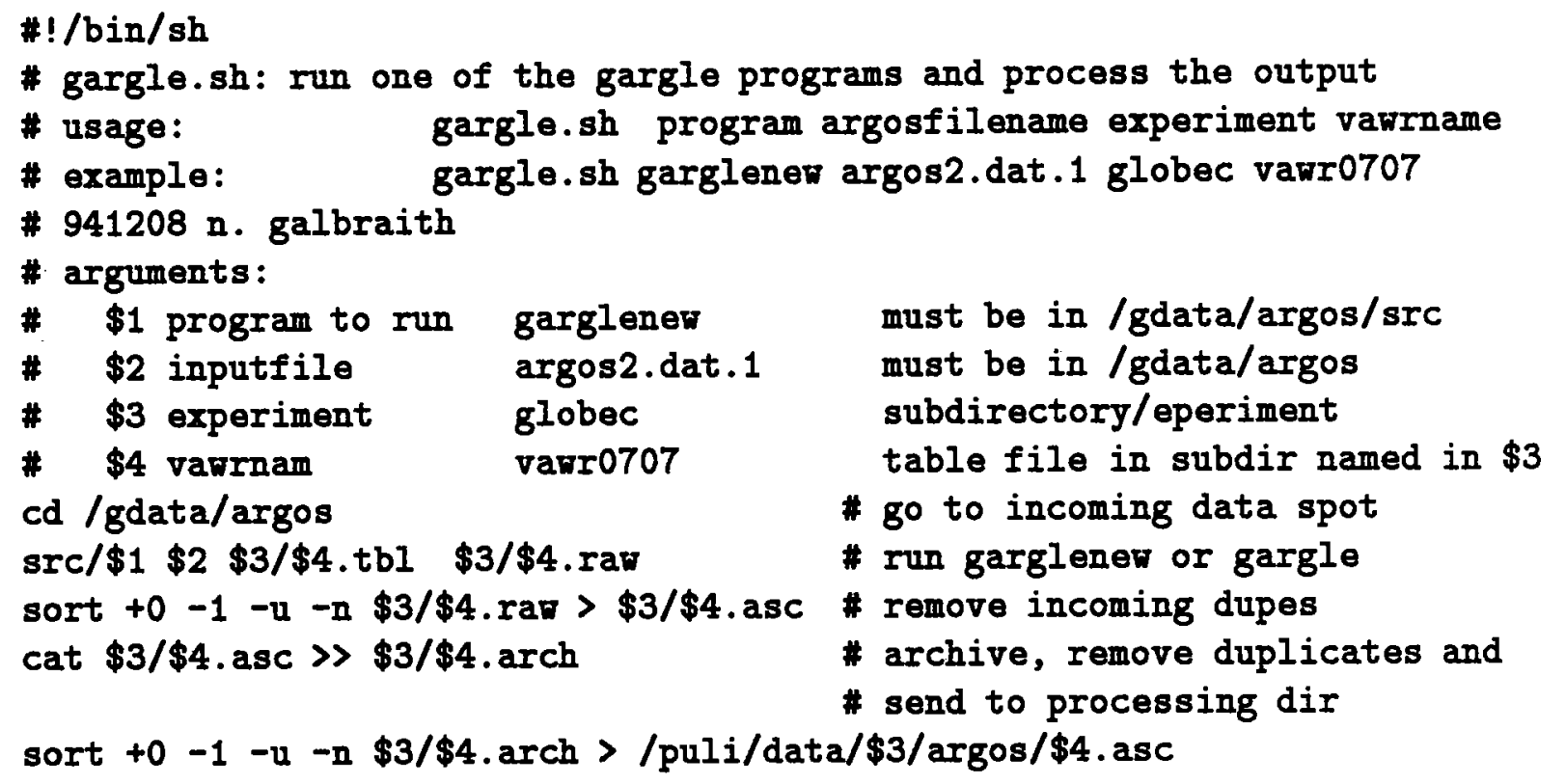

Appendix II.2. Gargle output

This is a sample output file containing VAWR data as written by program gargle. The variables are:

yearday east north speed dir sw rh bp seaT airT TPV bodyT domeT Iw $\mathrm{m} / \mathrm{s} \mathrm{m} / \mathrm{s} \quad \mathrm{m} / \mathrm{s}$ deg $\mathbf{w} / \mathrm{m}-2 \% \mathrm{mb} \quad \operatorname{degC} \operatorname{degC} \mathrm{mv} \quad \operatorname{DegK} \operatorname{DegK} w / \mathrm{m}-2$ $52.229,-4.79,1.66,5.07,25.8,-1,95.4,995.6,5.552,6.74,41.1,279.8,279.8,352.8$ $52.250,-3.78,2.41,4.48,37.5,-1,95.5,995.0,5.559,6.59,42.9,279.7,279.6,352.6$ $52.260,-3.37,2.86,4.42,29.6,-1,95.6,994.9,5.558,6.57,44.4,279.7,279.8,352.9$ $52.281,-2.70,4.11,4.92,13.3,-1,95.7,993.9,5.546,6.68,48.0,279.8,279.7,354.4$ 
Appendix II.3. VAWR Table File

$\rightarrow$ vavr_tabl :0721 : nan : Tue Jun 2894

\#0 : v721vr instrument identifier

01356 - PROGRAM

06856 - PTT

06857 - PTT

06858 - PTT

\#1 :EC east counts

$$
16 \text { - BITS_EC }
$$

-10.0 - MIN_EC

30.0 - MAX_EC

-99.0 - MISS_EC

\#2 :NC north counts

16 - BITS_NC

-10.0 - MIN_NC

30.0 - MAX_NC

-99.0 - MISS_NC

\#3 :RC rotor counts

$$
16 \text { - BITS_RC }
$$

-10.0 - MIN_RC

30.0 - MAX_RC

-99.0 - MISS_RC

\#4 :CO CO counts

$$
\begin{aligned}
8 & - \text { BITS_CO } \\
-10.0 & - \text { MIN_CO } \\
30.0 & - \text { MAX_CO } \\
-99.0 & - \text { MISS_CO } \\
-.8 & - \text { MAGVAR }
\end{aligned}
$$

\#5 :VA vane counts

$$
\begin{array}{r}
8 \text { - BITS_VA } \\
-10.0 \text { - MIN_VA } \\
30.0 \text { - MAX_VA } \\
-99.0 \text { - MISS_VA }
\end{array}
$$

\#6 :TM time 


$$
\begin{aligned}
& 16 \text { - BITS_TM } \\
& 19920101 \text { - MIN_TM } \\
& 19941231 \text { - MAX_TM } \\
& \text {-99.0 - MISS_TM } \\
& 450 \text { - TSAMP } \\
& 450 \text { - CHIS } \\
& 94 \text { - YEAR } \\
& 10 \text { - MONTH } \\
& 02 \text { - DAY } \\
& 06 \text { - HOUR } \\
& 30 \text { - MINUTE } \\
& 00 \text { - SECOND } \\
& 20 \text { - BITS_SW } \\
& -10.0 \text { - MIN_SW } \\
& 1500.0 \text { - MAX_SW } \\
& \text {-99.0 - MISS_SW } \\
& 25418 \text { - \#_SW } \\
& 10.52 \text { - CAL_SW } \\
& 4.0 \text { - Z_SH } \\
& 20 \text { - BITS_LW } \\
& 100.0 \text { - MIN_LW } \\
& 500.0 \text { - MAX_LH } \\
& \text {-99.0 - MISS_LH } \\
& 28463 \text { - \#_TP } \\
& 2.04164 \text { - LH_A } \\
& 1.11 \text { - LH_B } \\
& \text { 0. - LH_C } \\
& -1018.68 \text { - TP_A } \\
& 2.04164 \text { - TP_B } \\
& 16 \text { - BITS_RH } \\
& 2.0 \text { - MIN_RH } \\
& 115.0 \text { - MAX_RH } \\
& \text {-99.0 - MISS_RH } \\
& 034 \text { - \#_RH }
\end{aligned}
$$




$$
\begin{aligned}
& 5.0667^{\circ} \text { - A_RH } \\
& 0.04571 \text { - B_RH } \\
& -0.0012539 \text { - C_RH } \\
& 3.51563 \text { - TI_RH } \\
& 210.32 \text { - P20 } \\
& \text { 20. - P2OFACT } \\
& \text { \#10 :BP barometric pressure } \\
& 16 \text { - BITS_BP } \\
& 800.0 \text { - MIN_BP } \\
& 1100.0 \text { - MAX_BP } \\
& \text {-99.0 - MISS_BP } \\
& 43698 \text { - \#_BP } \\
& 0.0 \text { - A_BP } \\
& 0.0 \text { - B_BP } \\
& 92.68879 \text { - C1_BP } \\
& 2.672706-C_{2} \text { BP } \\
& -114.7084 \text { - C3_BP } \\
& 0.031184 \text { - D1_BP } \\
& \text { 27.92331E-06 - TO_BP } \\
& 2.636716 \text { - TI_BP } \\
& 27.85152 \text { - T1_BP } \\
& 0.831612 \text { - T2_BP } \\
& 20.34282 \text { - T3_BP } \\
& -4035.285 \text { - Y1_BP } \\
& 0.0-Y 1 \_B P \\
& -14001.10 \text { - Y2_BP } \\
& 20 \text { - BITS_SEA } \\
& -10.0 \text { - MIN_SEA } \\
& 40.0 \text { - MAX_SEA } \\
& \text {-99.0 - MISS_SEA } \\
& 5005 \text { - \#_SEA } \\
& 9038.16 \text { - R1_SEA } \\
& 3998.49 \text { - R2_SEA } \\
& -1.45 \text { - F1_SEA } \\
& 759.14 \text { - F2_SEA } \\
& .109376436 \mathrm{E}-02 \text { - TA_SEA }
\end{aligned}
$$




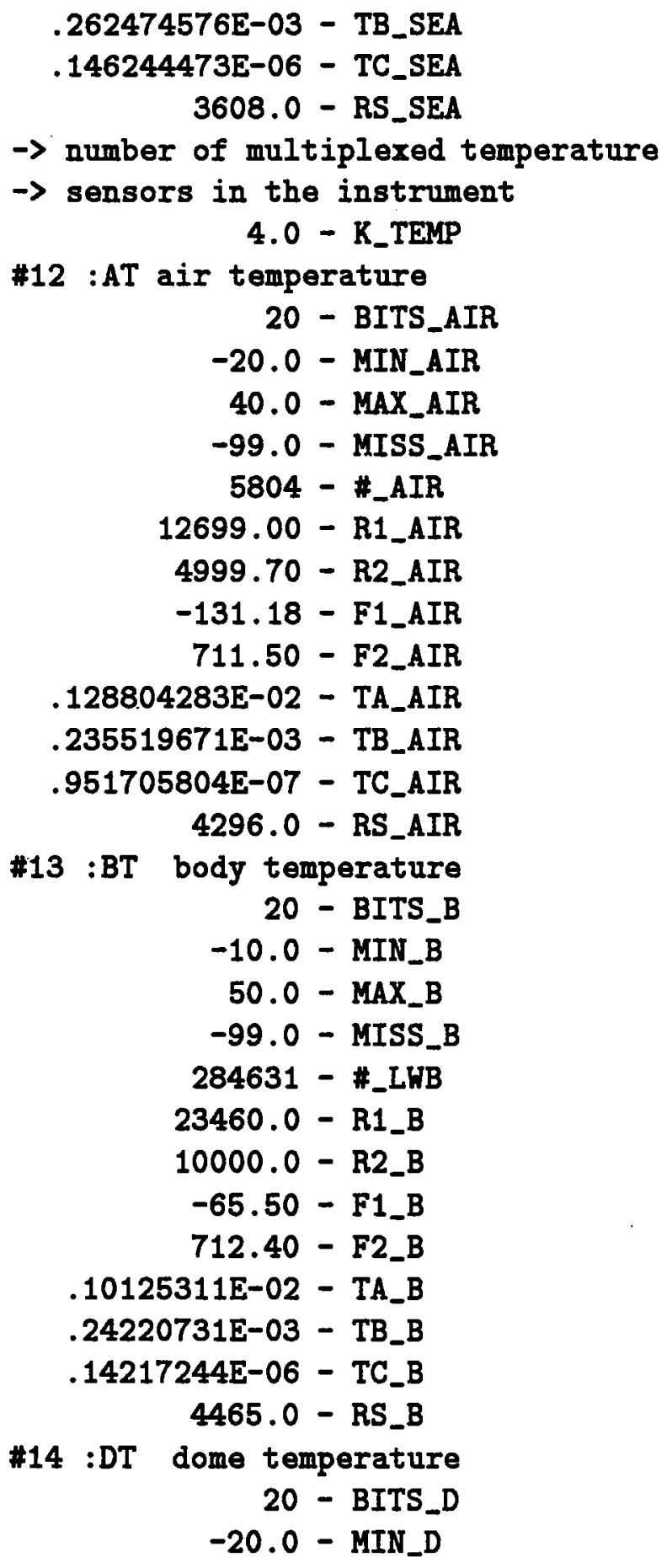




$$
\begin{aligned}
& 50.0 \text { - MAX_d } \\
& \text {-99.0 - MISS_D } \\
& 284632 \text { - \#_LWD } \\
& 23460.0 \text { - R1_D } \\
& 10000.0 \text { - R2_D } \\
& -66.56 \text { - F1_D } \\
& 711.49 \text { - F2_D } \\
& .10161020 \mathrm{E}-02 \text { - TA_D } \\
& .24160036 \mathrm{E}-03 \text { - TB_D } \\
& .14344824 E-06 \text { - TC_D } \\
& 4450.0 \text { - RS_D } \\
& \text { \#15 :DU filler engineering byte } \\
& 8 \text { - BITS_DUM } \\
& \text { \#16 :CS checksum } \\
& 16 \text { - BITS_CHECKSUM } \\
& \rightarrow \quad / * \text { must be 1st non standard const } * / \\
& 30 \text { - LST_BYT } \\
& \rightarrow \quad / * \text { must be } 2 \text { nd const, } 0 \text {-bin } 1 \text {-asc */ } \\
& 1 \text { - ASCII }
\end{aligned}
$$


Appendix III. IMET Processing

Appendix III.1. Shell Script Imet.sh

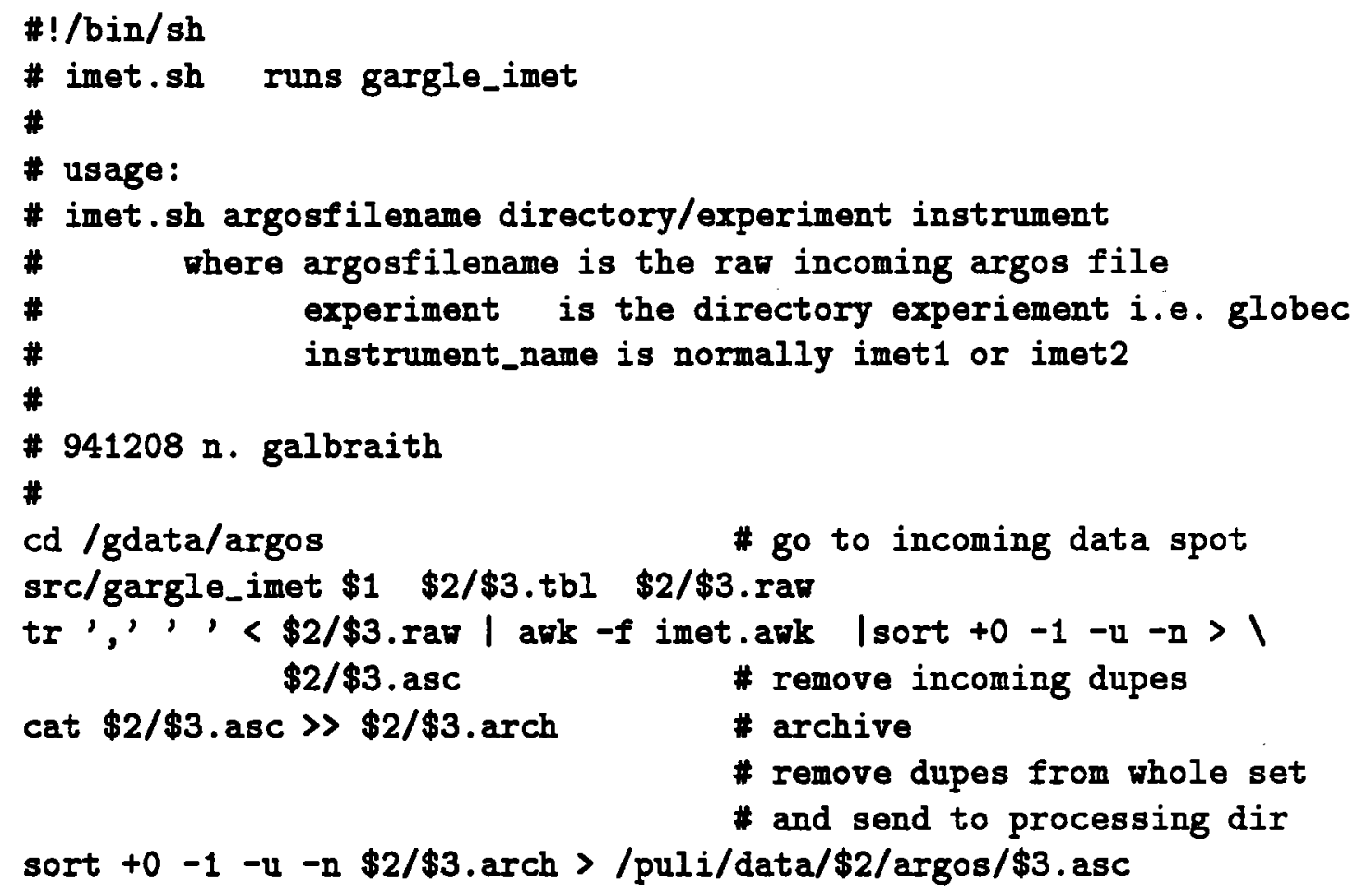


Appendix III.2. Imet.awk

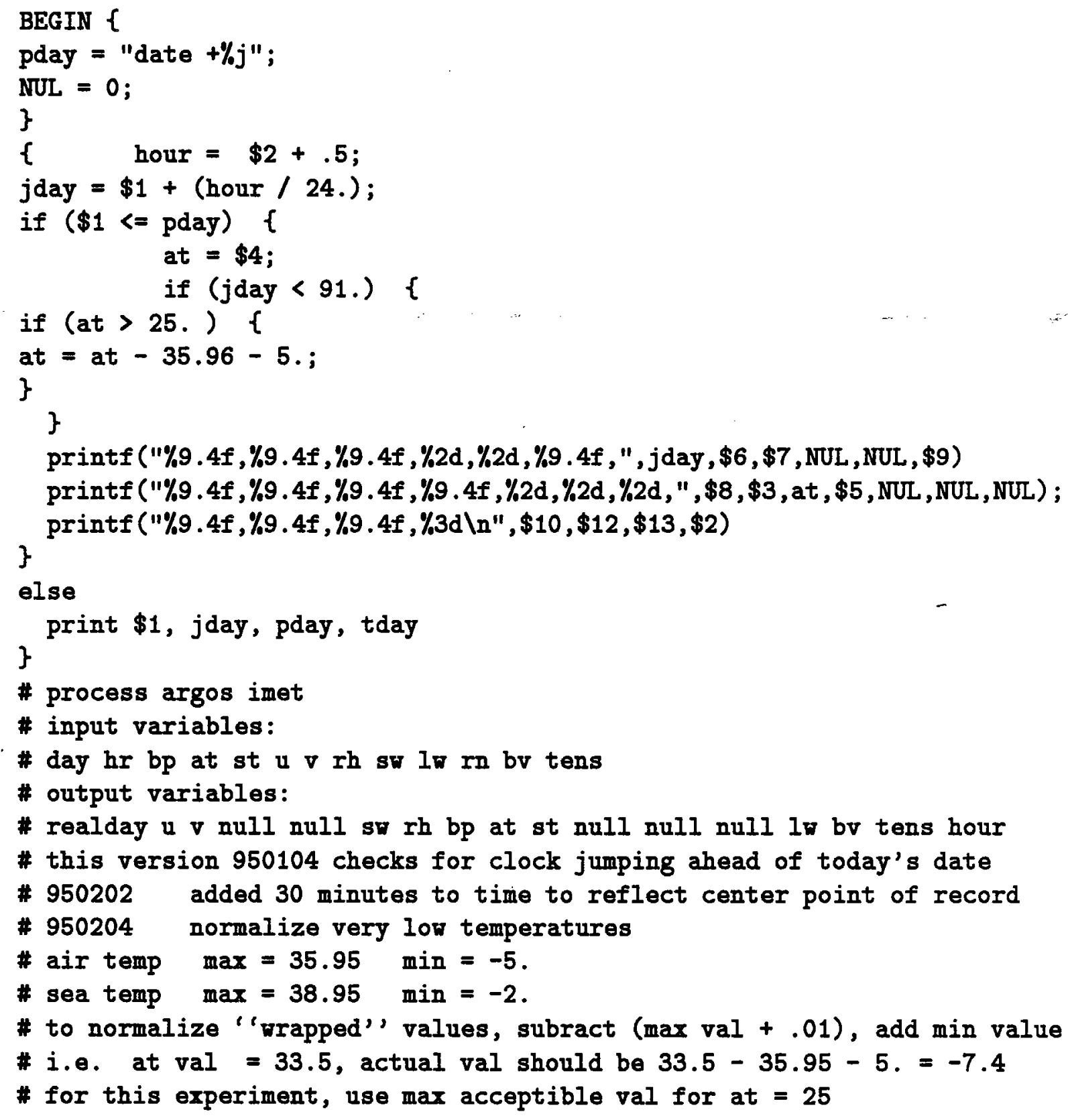




\section{Appendix III.3 Sample IMET File}

Variables labelled d are dummy variables.

yearday $u \quad v \quad d d s w \quad r h \quad b p \quad \operatorname{airT} s e a T d d d l w \quad b v$ tns prc $\mathrm{m} / \mathrm{s} \mathrm{m} / \mathrm{s} \quad \forall / \mathrm{m}^{\wedge} 2 \% \mathrm{mb} \quad \operatorname{degc} \operatorname{degc} \quad w / \mathrm{m}^{\wedge} 2 \mathrm{v} \quad 1 \mathrm{bs} \mathrm{mm}$

$53.1042,-5.00,5.30,0,0,0.0,91.0,995.8,3.10,5.46,0,0,0,321.0,13 ., 3450 ., 0$ $53.1458,-4.10,7.00,0,0,0.0,90.0,996.0,2.95,5.46,0,0,0,322.0,13 ., 3350 ., 9$ $53.1875,-3.30,8.20,0,0,0.0,91.0,996.2,2.55,5.53,0,0,0,320.0,13 ., 3300 ., 9$ $53.2292,-2.50,7.80,0,0,0.0,90.0,996.4,2.48,5.56,0,0,0,317.0,13 ., 3300 ., 13$ $53.2708,-3.30,8.00,0,0,0.0,88.0,996.8,2.46,5.63,0,0,0,313.0,13 ., 3050 ., 13$ $53.3125,-4.50,7.90,0,0,0.0,87.0,996.8,2.35,5.60,0,0,0,313.0,13 ., 3000 ., 0$ 
Appendix III.4. IMET Table File

-> imet_tabl :01419 : roger : Thu Dec 0895

\#0 : i01419 instrument identifier

01419 - PROGRAM

23657 - PTT

23658 - PTT

23659 - PTT

\#1 :DA day of year

09 - BITS_DA

1.0 - MIN_DA

365.0 - MAX_DA

-99.0 - MISS_DA

\#2 :HR hour of day

05 - BITS_HR

0.0 - MIN_HR

23.0 - MAX_HR

-99.0 - MISS_HR

\#3 :BP barometric pressure

11 - BITS_BP

900.0 - MIN_BP

1100.0 - MAX_BP

-99.0 - MISS_BP

\#4 :AT air temperature

12 - BITS_AT

-5.0 - MIN_AT

35.0 - MAX_AT

-99.0 - MISS_AT

0.01 - SCALE_AT

500.0 - BIAS_AT

\#5 :WT sea temperature

12 - BITS_HT

-2.0 - MIN_WT

38.0 - MAX_WT

-99.0 - MISS_HT

0.01 - SCALE_WT 
200.0 - BIAS_WT

\#6 : WU Wind $U$

$$
\begin{aligned}
10 & - \text { BITS_WU } \\
-51.5 & - \text { MIN_WU } \\
51.5 & - \text { MAX_WU } \\
-99.0 & - \text { MISS_WU } \\
0.1 & - \text { SCALE_WU } \\
511.0 & - \text { BIAS_WU }
\end{aligned}
$$

\#7 :WV Wind V

$$
\begin{aligned}
10 & - \text { BITS_WV } \\
-51.5 & - \text { MIN_WV } \\
51.5 & - \text { MAX_WV } \\
-99.0 & - \text { MISS_WV } \\
0.1 & - \text { SCALE_WV } \\
511.0 & - \text { BIAS_WV }
\end{aligned}
$$

\#8 : $\mathrm{RH}$ relative humidity

$$
7 \text { - BITS_RH }
$$

0.0 - MIN_RH

100.0 - MAX_RH

-99.0 - MISS_RH

\#9 :SW short vave radiation

$$
\begin{array}{r}
11 \text { - BITS_SW } \\
0.0 \text { - MIN_SW } \\
1500.0 \text { - MAX_SW } \\
-99.0 \text { - MISS_SW }
\end{array}
$$

\#10 :LW long rave radiation

$$
10 \text { - BITS_LH }
$$

0.0 - MIN_LW

750.0 - MAX_LH

$$
\text { -99.0 - MISS_LW }
$$

\#11 :RN precipitation

$$
\begin{aligned}
7 & \text { - BITS_RN } \\
0.0 & \text { - MIN_RN } \\
127.0 & \text { - MAX_RN } \\
-99.0 & \text { - MISS_RN }
\end{aligned}
$$

\#12 :BV battery voltage

$$
8 \text { - BITS_BV }
$$




$$
\begin{array}{r}
-20.0 \text { - MIN_BV } \\
15.0 \text { - MAX_BV } \\
-99.0 \text { - MISS_BV } \\
0.1 \text { - SCALE_BV }
\end{array}
$$

\#13 :TN tension

$$
\begin{aligned}
& 8 \text { - BITS_TN } \\
& -20.0 \text { - MIN_TN }
\end{aligned}
$$$$
12750.0 \text { - MAX_TN }
$$$$
-99.0 \text { - MISS_TN }
$$

50.0 - SCALE_TN

$\rightarrow$ NOTE: the cycle repeats, identical values

\#14 :D2 day of year

$$
\begin{array}{r}
09 \text { - BITS_DA } \\
1.0 \text { - MIN_DA } \\
365.0 \text { - MAX_DA } \\
-99.0 \text { - MISS_DA }
\end{array}
$$

\#15 :H2. hour of day

$$
\text { O5 - BITS_HR }
$$

$$
0.0 \text { - MIN_HR }
$$$$
23.0 \text { - MAX_HR }
$$$$
-99.0 \text { - MISS_HR }
$$

\#16 :B2 barometric pressure

$$
\begin{array}{r}
11 \text { - BITS_BP } \\
900.0 \text { - MIN_BP } \\
1100.0 \text { - MAX_BP } \\
-99.0 \text { - MISS_BP }
\end{array}
$$

\#17 :A2 air temperature

12 - BITS_AT

-5.0 - MIN_AT

35.0 - MAX_AT

-99.0 - MISS_AT

0.01 - SCALE_AT

500.0 - BIAS_AT

\#18 :W2 sea temperature

$$
12 \text { - BITS_WT }
$$

-2.0 - MIN_WT

38.0 - MAX_HT 


$$
\begin{gathered}
-99.0 \text { - MISS_WT } \\
0.01 \text { - SCALE_WT } \\
200.0 \text { - BIAS_WT }
\end{gathered}
$$

\#19:02 Hind U

$$
\begin{aligned}
10 & - \text { BITS_WU } \\
-51.1 & - \text { MIN_WU } \\
51.1 & - \text { MAX_WU } \\
-99.0 & - \text { MISS_WU } \\
0.1 & \text { - SCALE_WU } \\
511.0 & - \text { BIAS_WU }
\end{aligned}
$$

\#20 :V2 Wind V

$$
\begin{aligned}
10 & - \text { BITS_WV } \\
-51.1 & - \text { MIN_WV } \\
51.1 & - \text { MAX_WV } \\
-99.0 & \text { - MISS_WV } \\
0.1 & \text { - SCALE_WV } \\
511.0 & \text { - BIAS_WV }
\end{aligned}
$$

\#21 :R2 relative humidity

$$
\begin{aligned}
7 & - \text { BITS_RH } \\
0.0 & - \text { MIN_RH } \\
100.0 & - \text { MAX_RH } \\
-99.0 & \text { - MISS_RH }
\end{aligned}
$$

\#22 :S2 short wave radiation

$$
\begin{aligned}
11 & - \text { BITS_SW } \\
0.0 & - \text { MIN_SW } \\
1500.0 & - \text { MAX_SW } \\
-99.0 & - \text { MISS_SW }
\end{aligned}
$$

\#23 :L2 long wave radiation

$$
\begin{gathered}
10 \text { - BITS_LW } \\
0.0 \text { - MIN_LH } \\
750.0 \text { - MAX_LH } \\
-99.0 \text { - MISS_LW }
\end{gathered}
$$

\#24 :P2 precipitation

$$
\begin{aligned}
7 & \text { - BITS_RN } \\
0.0 & - \text { MIN_RN } \\
127.0 & - \text { MAX_RN } \\
-99.0 & \text { - MISS_RN }
\end{aligned}
$$




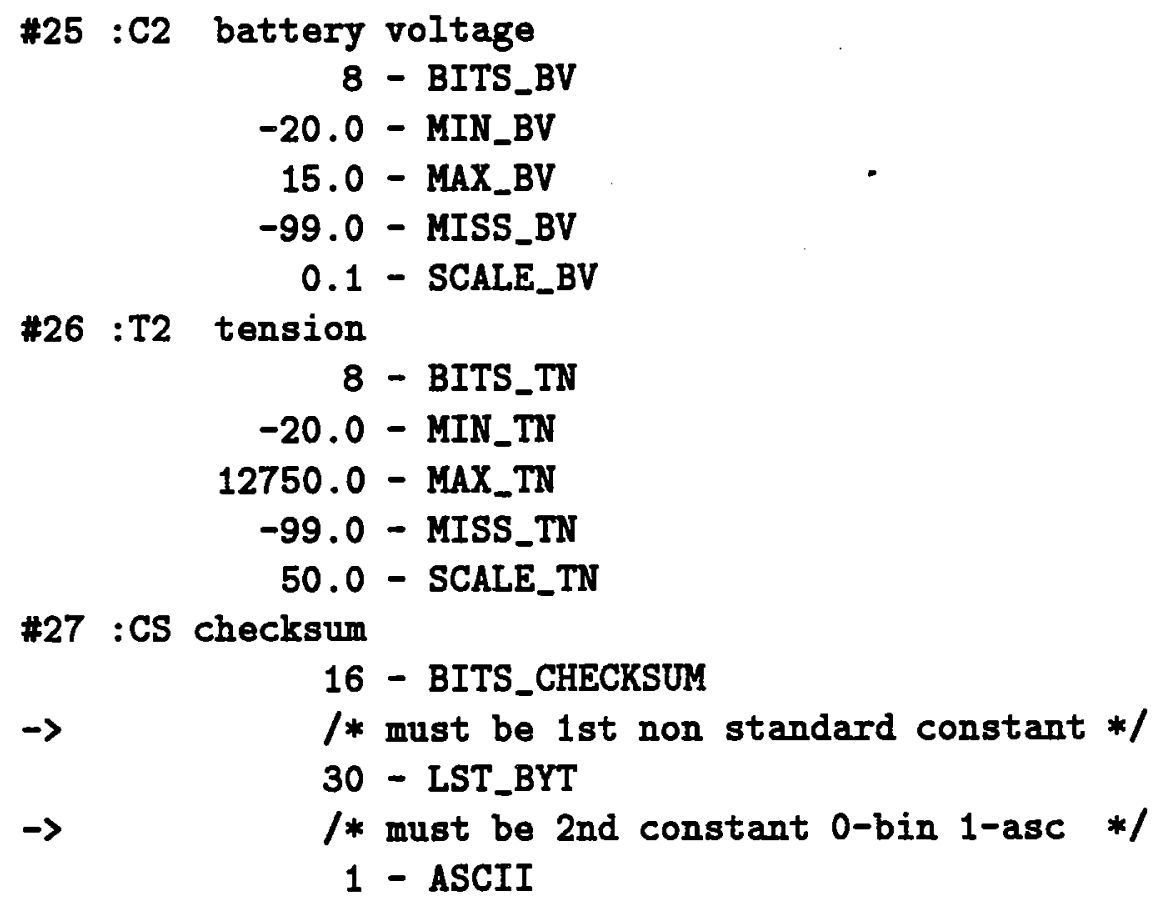


Appendix IV. Engineering PTT Processing

Appendix IV.1. Shell Script dotens.sh

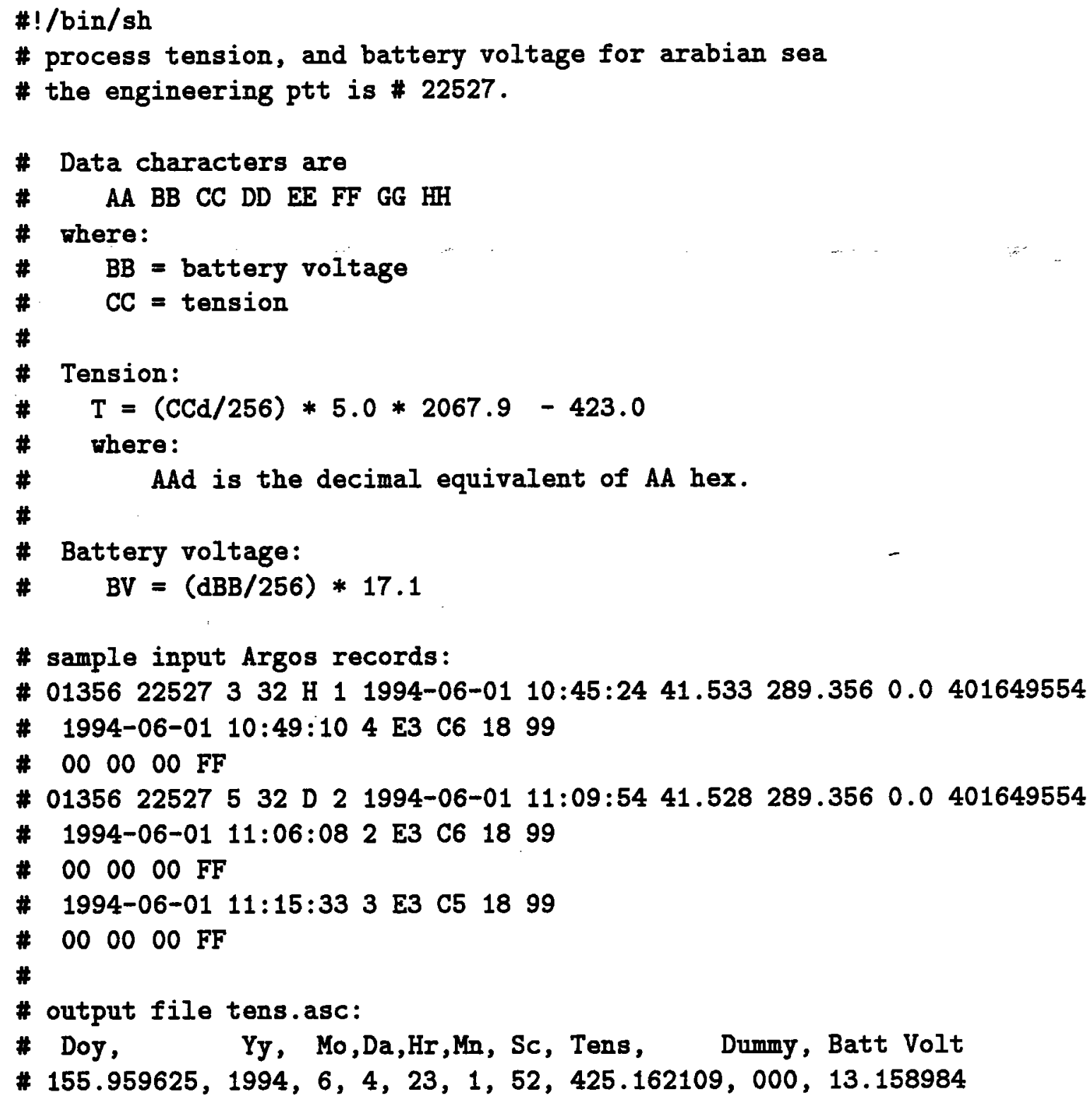




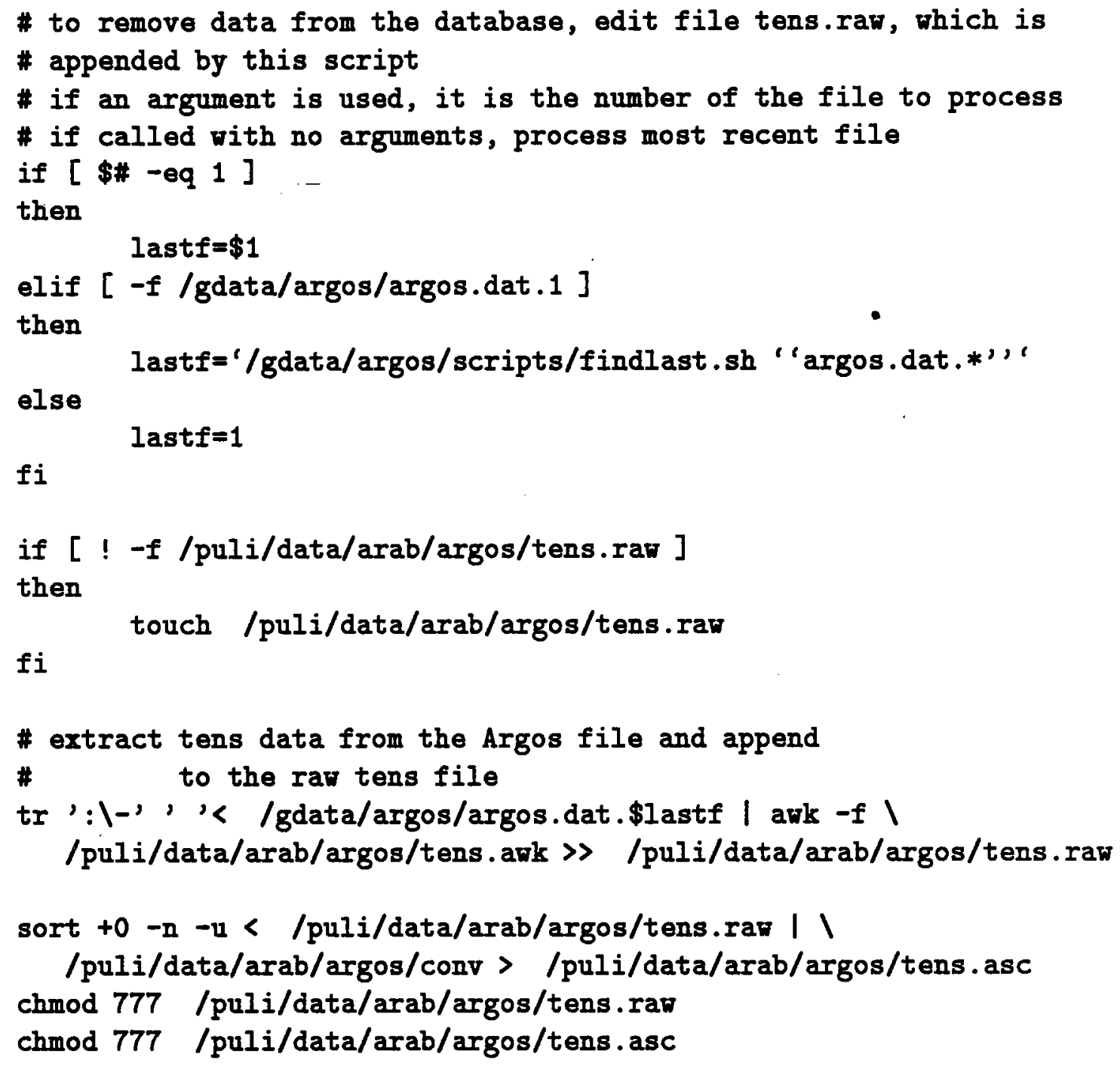


Appendix IV.2. Awk Script tens.awk

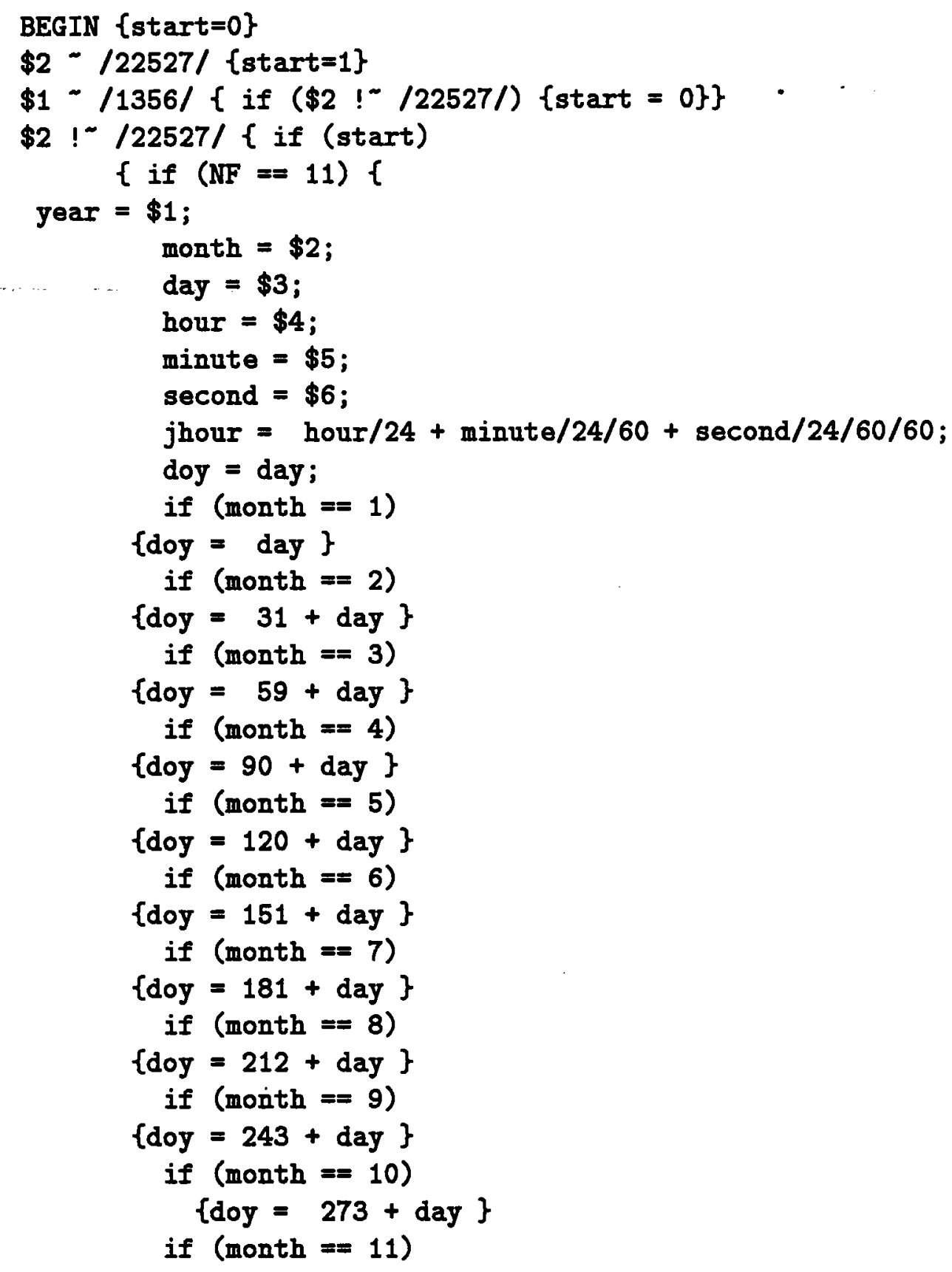




$$
\begin{gathered}
\{\text { doy }=304+\text { day }\} \\
\text { if (month }==12) \\
\{\text { doy }=334+\text { day }\} \\
\text { doy }=\text { doy + jhour }
\end{gathered}
$$

printf ("\%f \%d \%d \%d \%d \%d \%d \%s \%s \%s n",

doy, $\$ 1, \$ 2, \$ 3, \$ 4, \$ 5, \$ 6, \$ 9, \$ 10, \$ 11)\}$

\}

\} 


\section{Appendix IV.3. Program Conv.c}

This program is used by the shell script dotens.sh to decode the ASCII hexadecimal values in the tensiometer PTT record.

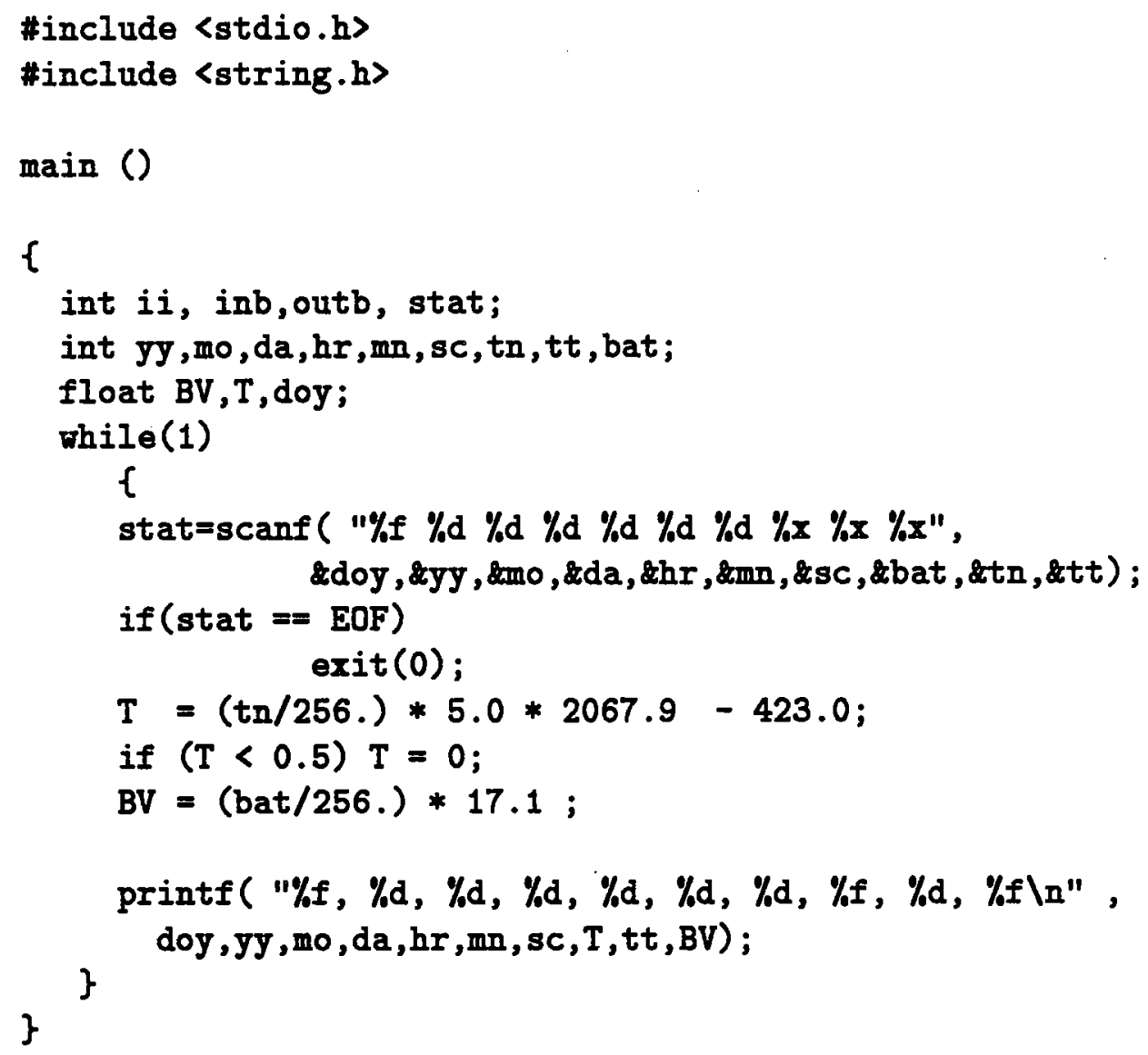


Appendix V. Position Processing Scripts

Appendix V.1. doposit.sh

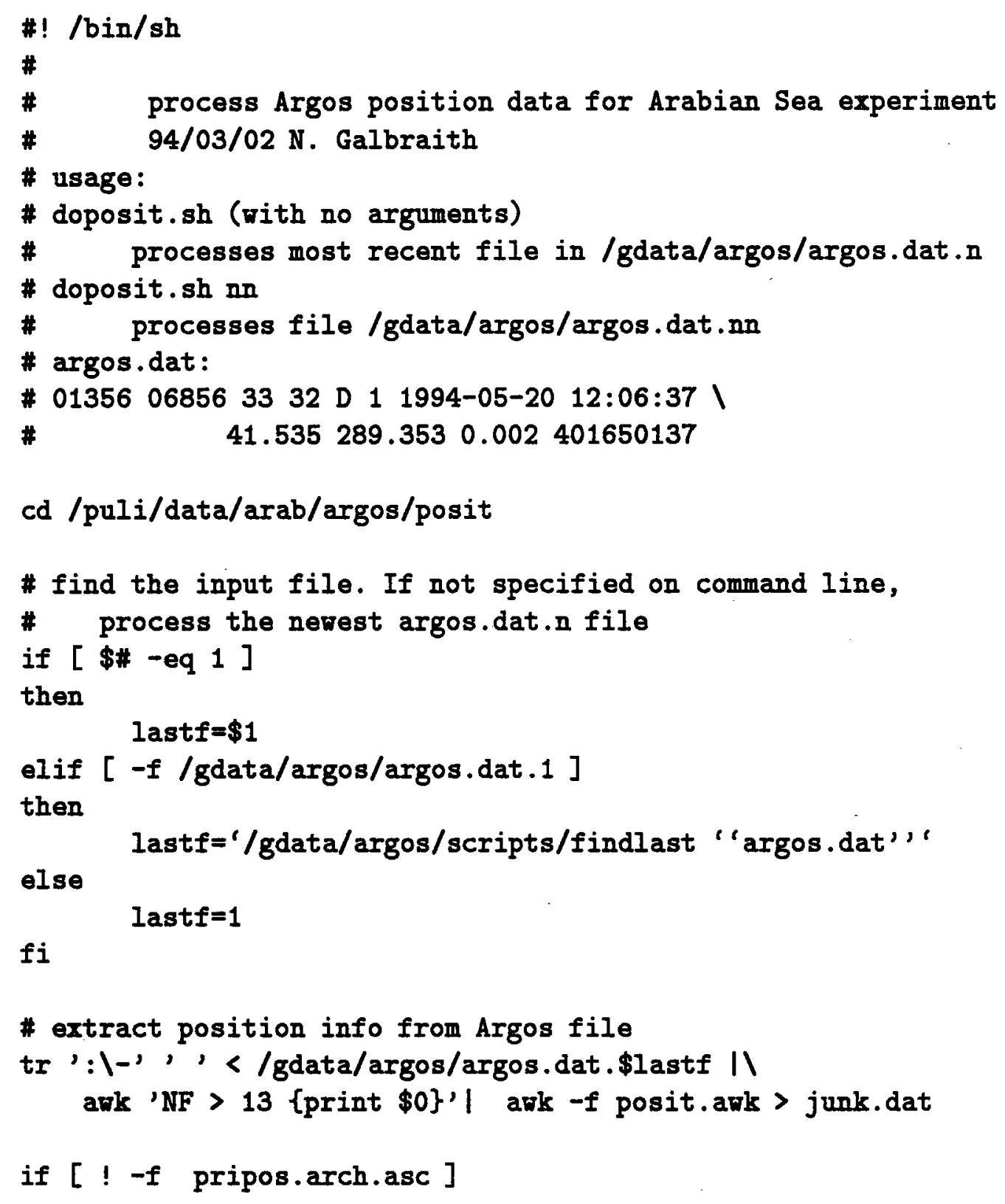




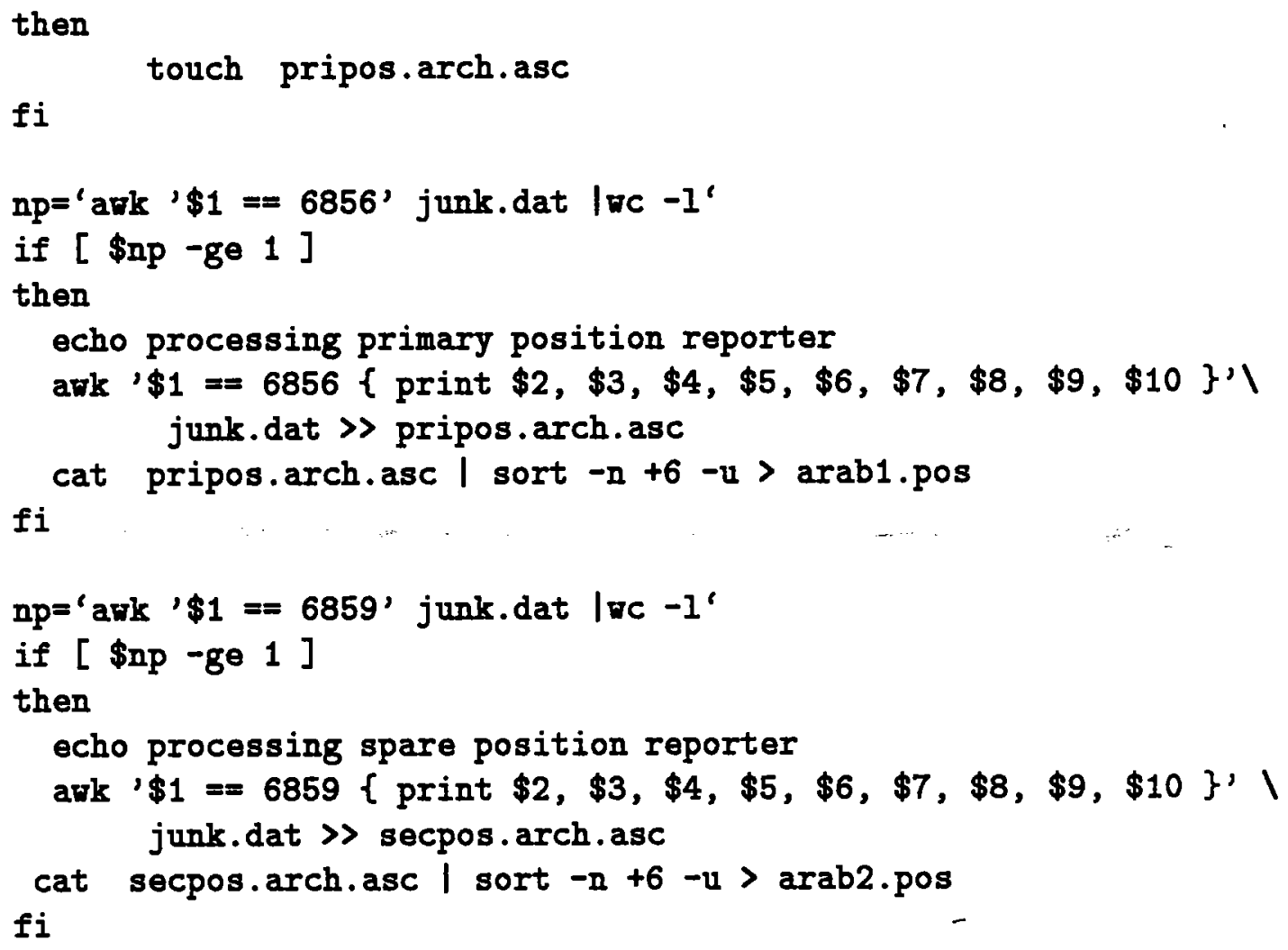


Appendix V.2. posit.awk

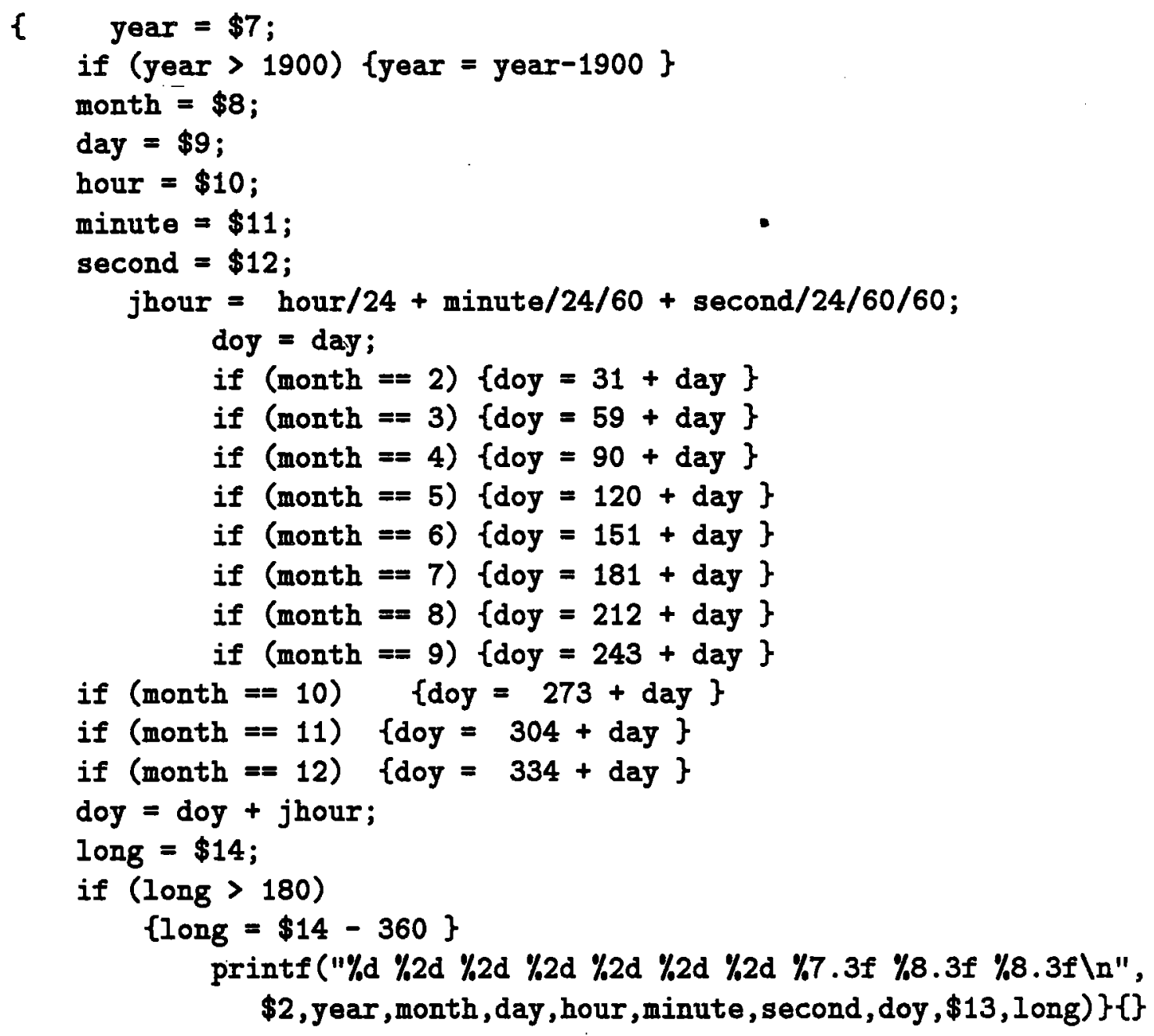


Appendix VI. Data Distribution Scripts

Appendix VI.1. Ftp Shell Script

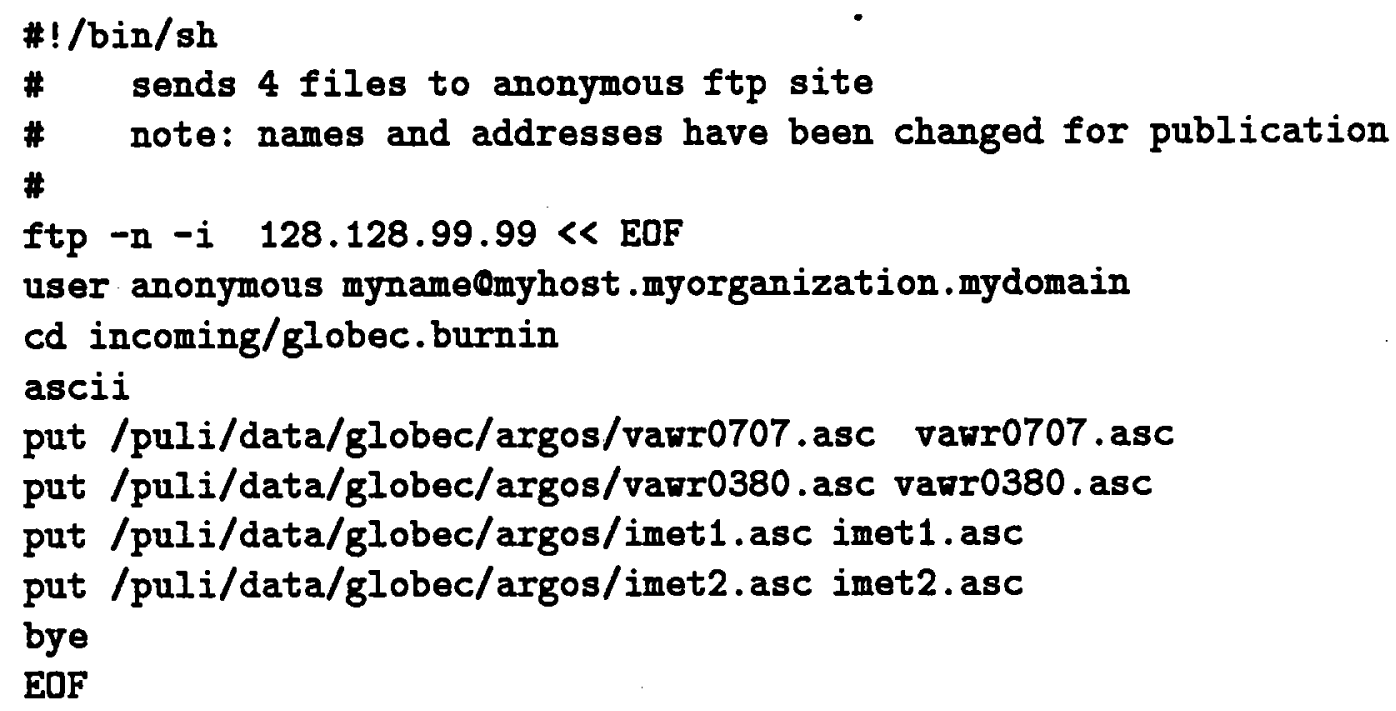




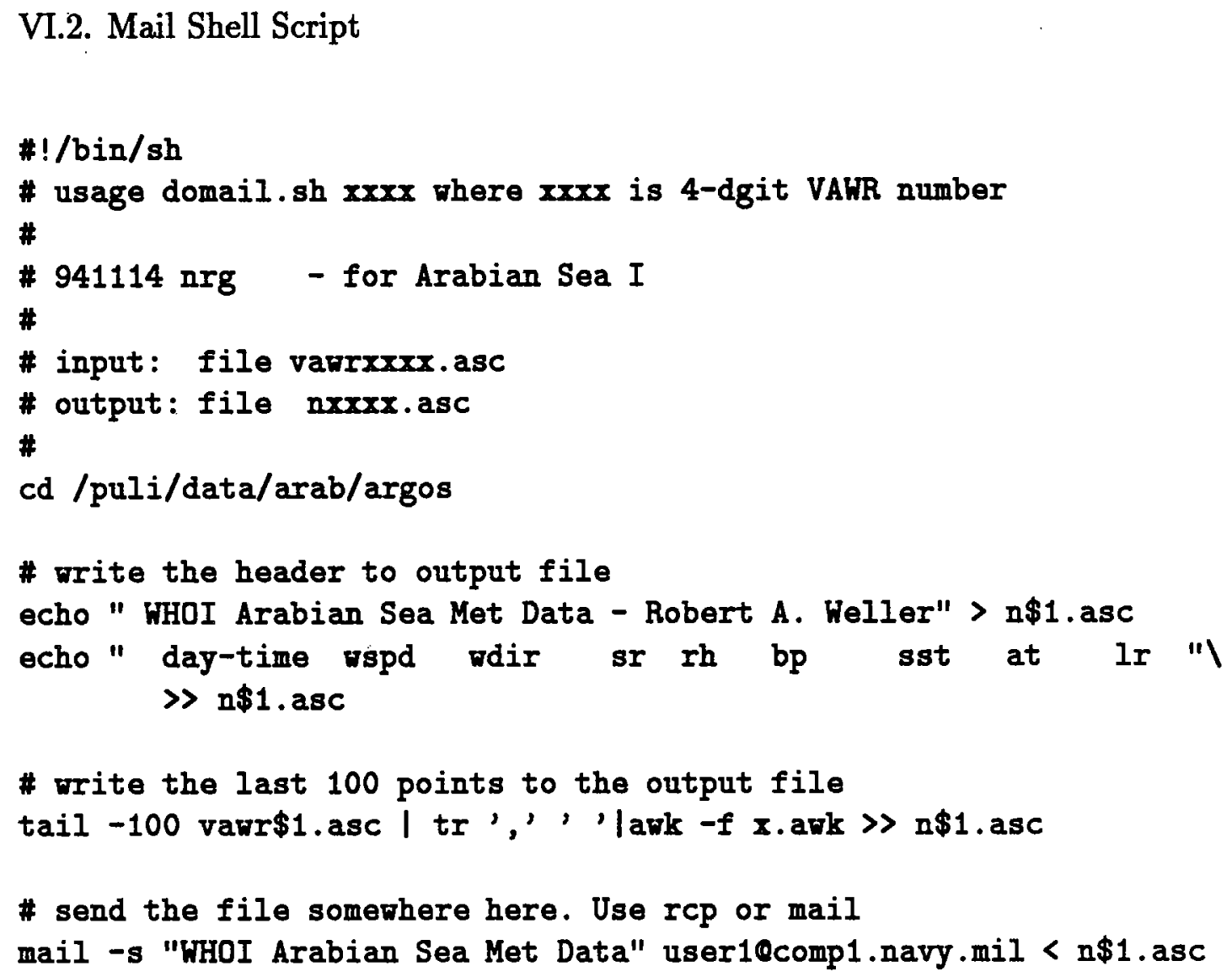

Appendix VI.3. x.awk

This one-line script extracts data variables of interest to be transmitted to remote sites.

$\{$ printf("\%10.6f \%5.2f \%7.2f \%4d \%4.1f \%6.1f \%5.2f \%5.2f \%5.1f \n", $\$ 1, \$ 4, \$ 5, \$ 6, \$ 7, \$ 8, \$ 9, \$ 10, \$ 14)\}$ 
Appendix VII. Plotting Scripts and Sample Plots

Appendix VII.1. Shell Script dopl.sh

Shell script dopl.sh plots VAWR and mooring information.

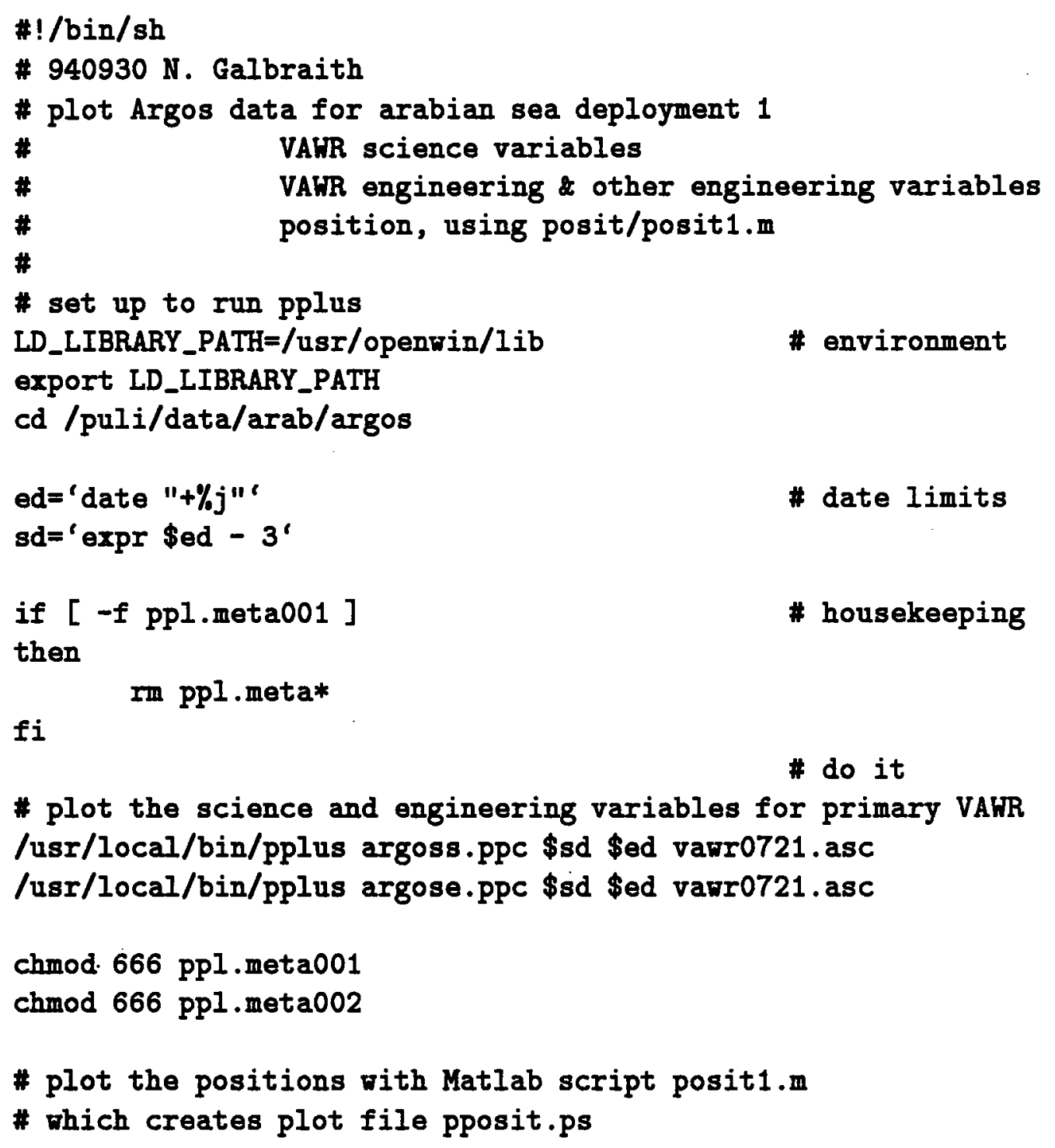


cd /puli/data/arab/argos/posit

/usr/local/bin/matlab <posit1.m chmod 666 pposit.ps

\# send the plotfiles to the printer

cd /puli/data/arab/argos

/usr/local/bin/m2ps -R ppl.meta001 I 1pr

if [ $f f \mathrm{ppl}$.meta002 ]

then

/usr/local/bin/m2ps -R ppl.meta002 | 1pr

fi

cd /puli/data/arab/argos/posit

lpr pposit.ps 
VII.2. Pplus Plotting Scripts

VII.2.1. Plot Scientific Variables: argoss.ppc

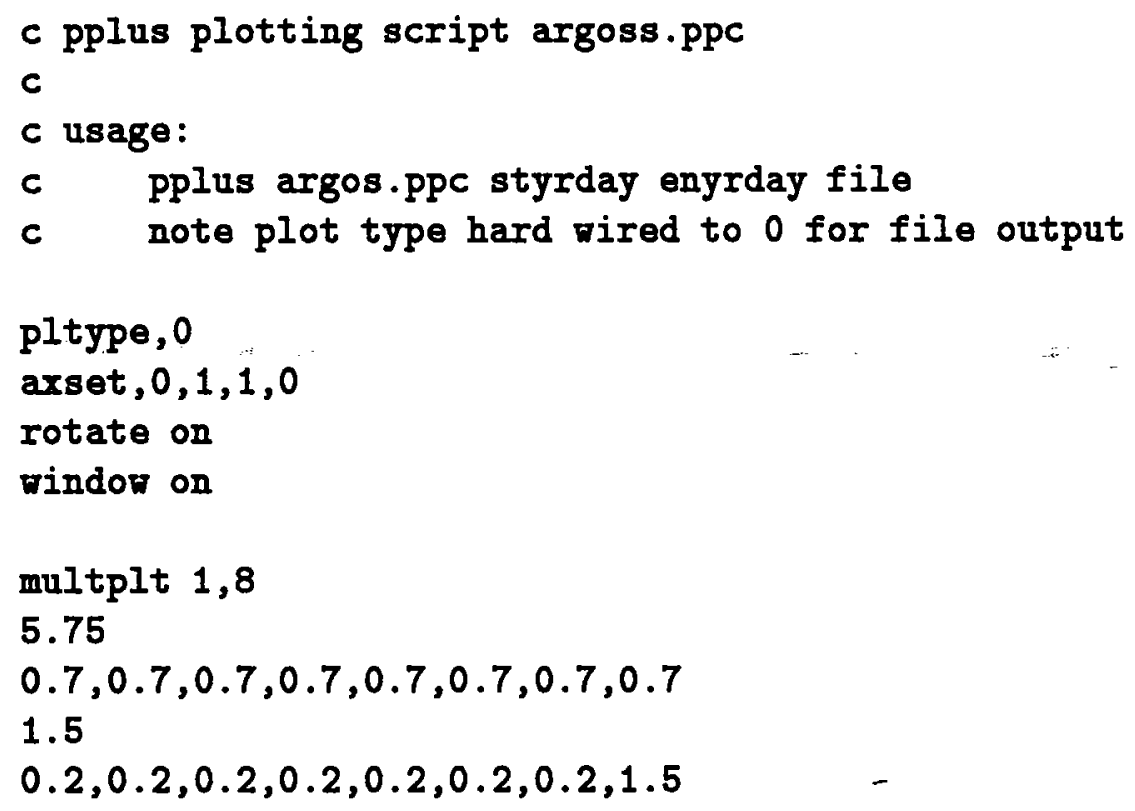

5.75 


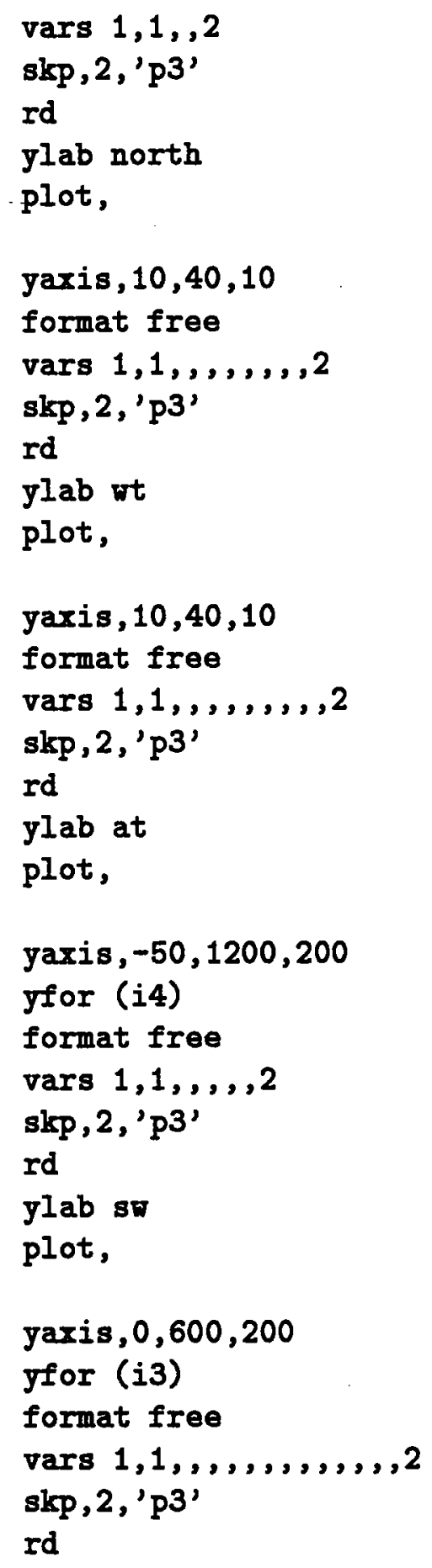


jlab 10

plot,

yaxis, $1000,1040,10$,

yfor (i4)

format free

vars $1,1,,,,,,, 2$

skp , 2 , 'p3'

rd

ylab,bp

plot,

axlabp $-1,-1$

yaxis, $0,100,20$

yfor (i3)

format free

vars $1,1, \ldots,, 2$

skp, 2 , 'p3'

rd

ylab, rh

plot,Arabian Sea Argos 'p3' 


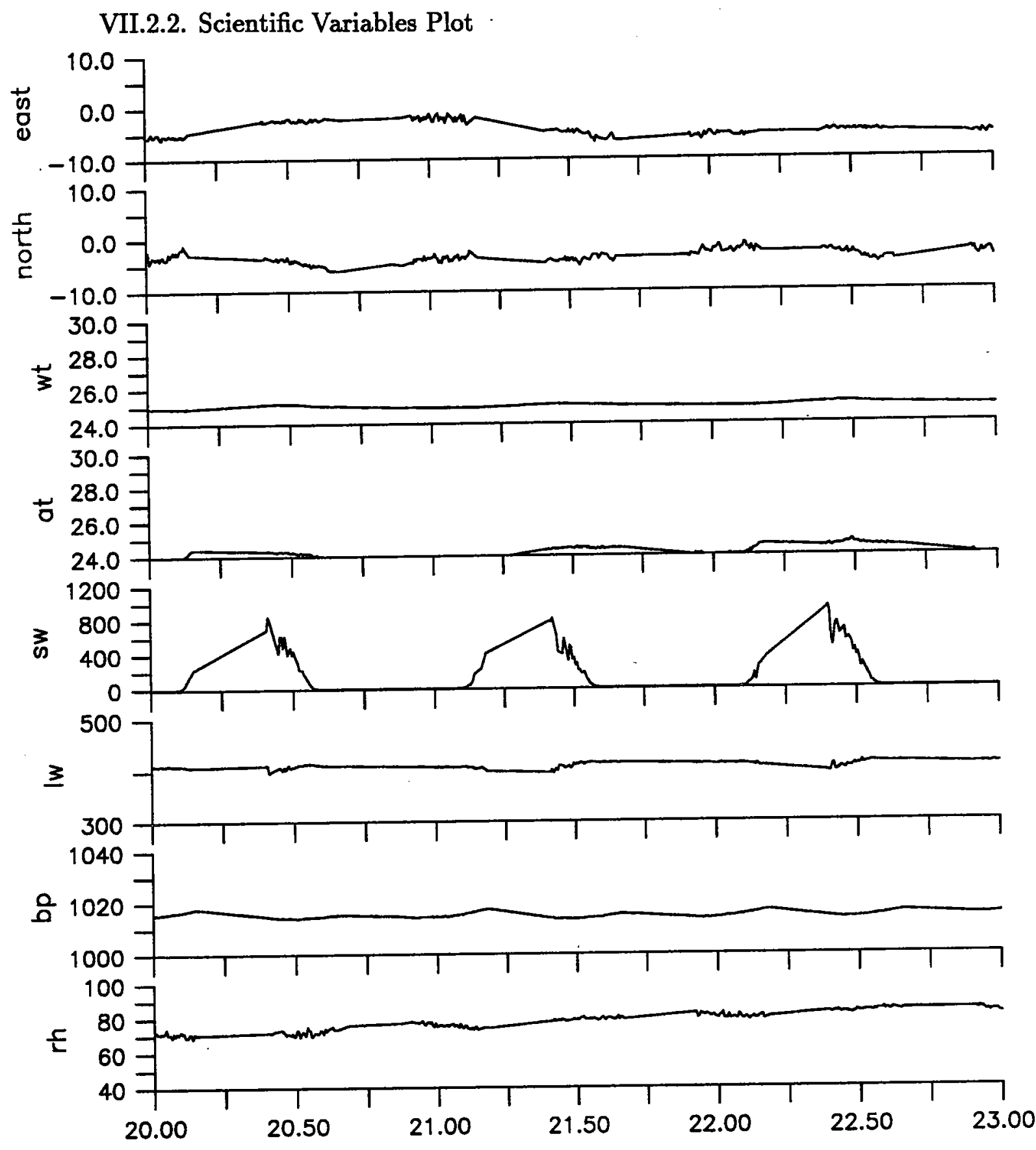

Arabian Sea Argos vawr0721.asc 
VII.2.3. Plot Engineering Variables: argose.ppc

c plot VAHR Argos engineering data for Arabian Sea c usage: pplus argos.ppc styrday enyrday file pltype, 0 axset, $0,1,1,0$ multplt 1,7

5.75

$0.7,0.7,0.7,0.7,0.7,0.7,0.7$

1.5

$0.2,0.2,0.2,0.2,0.2,0.2,1.5$

line 1,0

xaxis 'p1', 'p2', . 25

vindow on

axlabp, $0,-1$

yaxis, $0,10,1$

format free

vars $1,1, \ldots, 2$

skp, 2 , ' $\mathrm{p} 3$ '

rd

ylab, spd

plot,

yaxis, $0,360,90$

vars $1,1, \ldots, 2$

skp, 2 , 'p3'

rd

ylab,dir

plot,

yaxis, $-200,400,100$

vars $1,1, \ldots, \ldots,,,,, 2$

skp, 2 , 'p3'

rd

ylab,tpile 


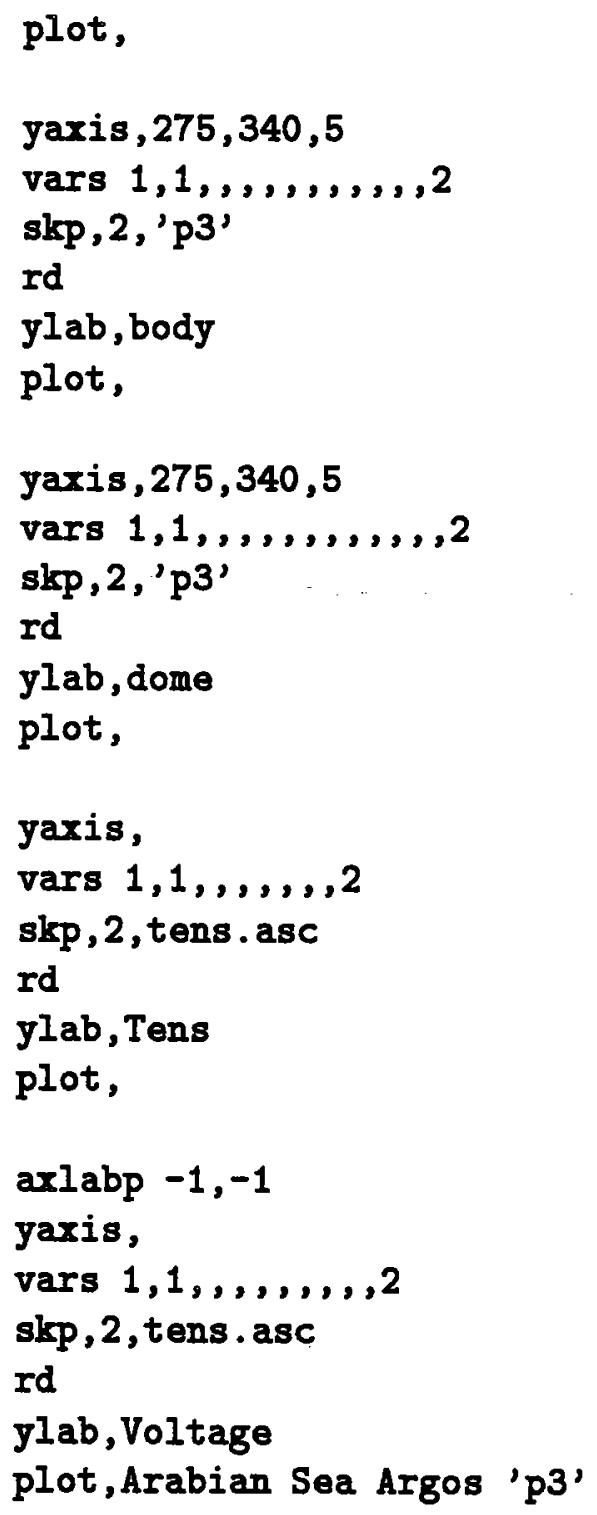




\section{VII.2.4. Engineering Variables Plot}
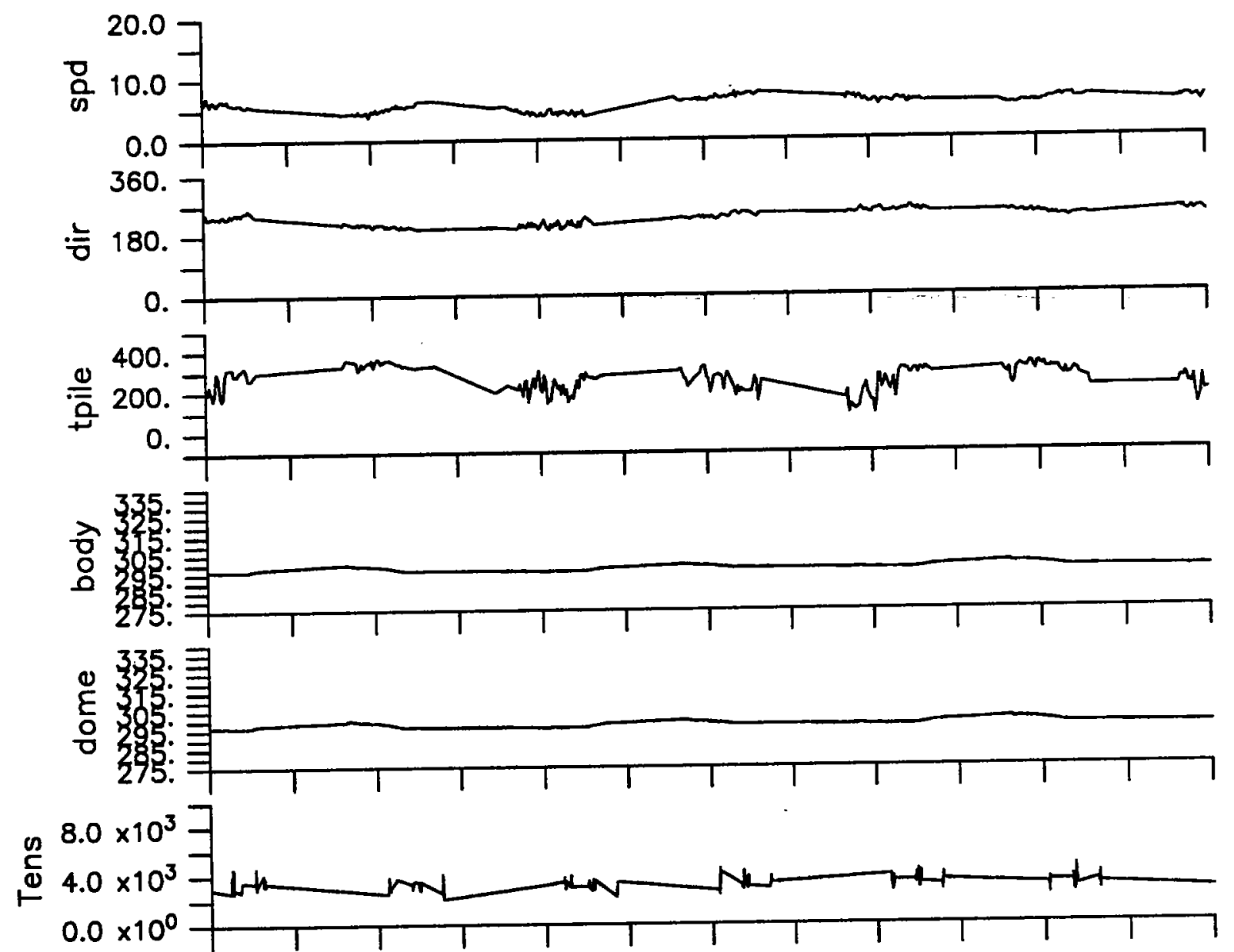

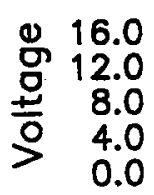

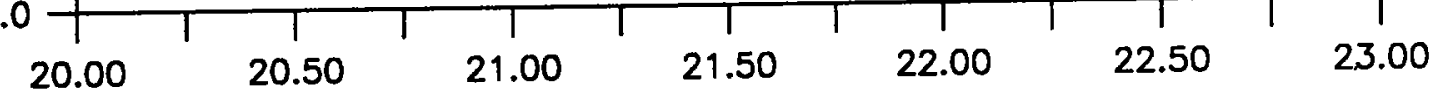

Arabian Sea ARGOS vawr0721.asc 
VII.3. Matlab Position Plotting Argos position values are plotted using Matlab noninteractively with script posit1.m.

VII.3.1 Matlab Script

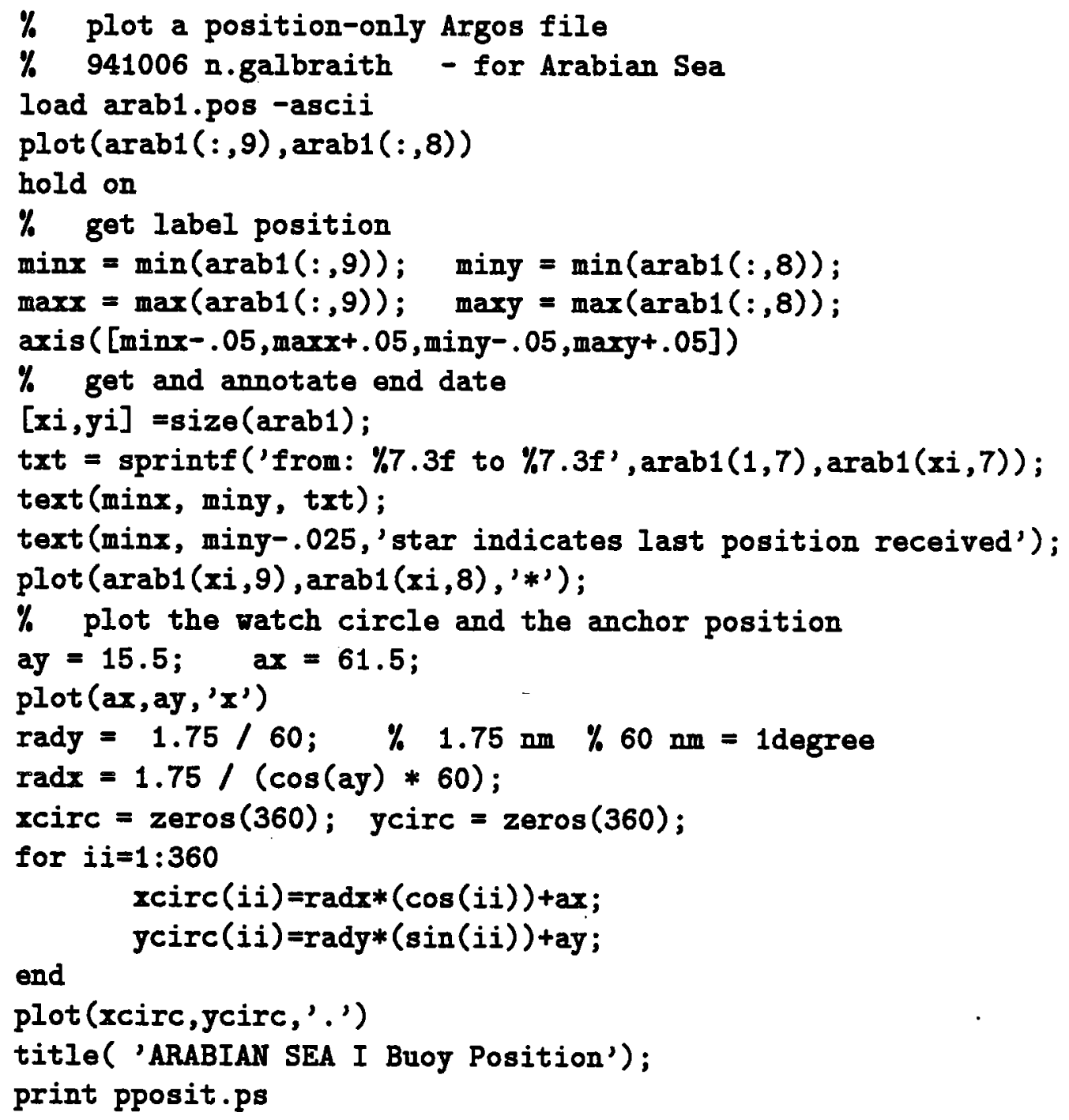


VII.3.1 Position Plot

ARABIAN SEA I Buoy Positions

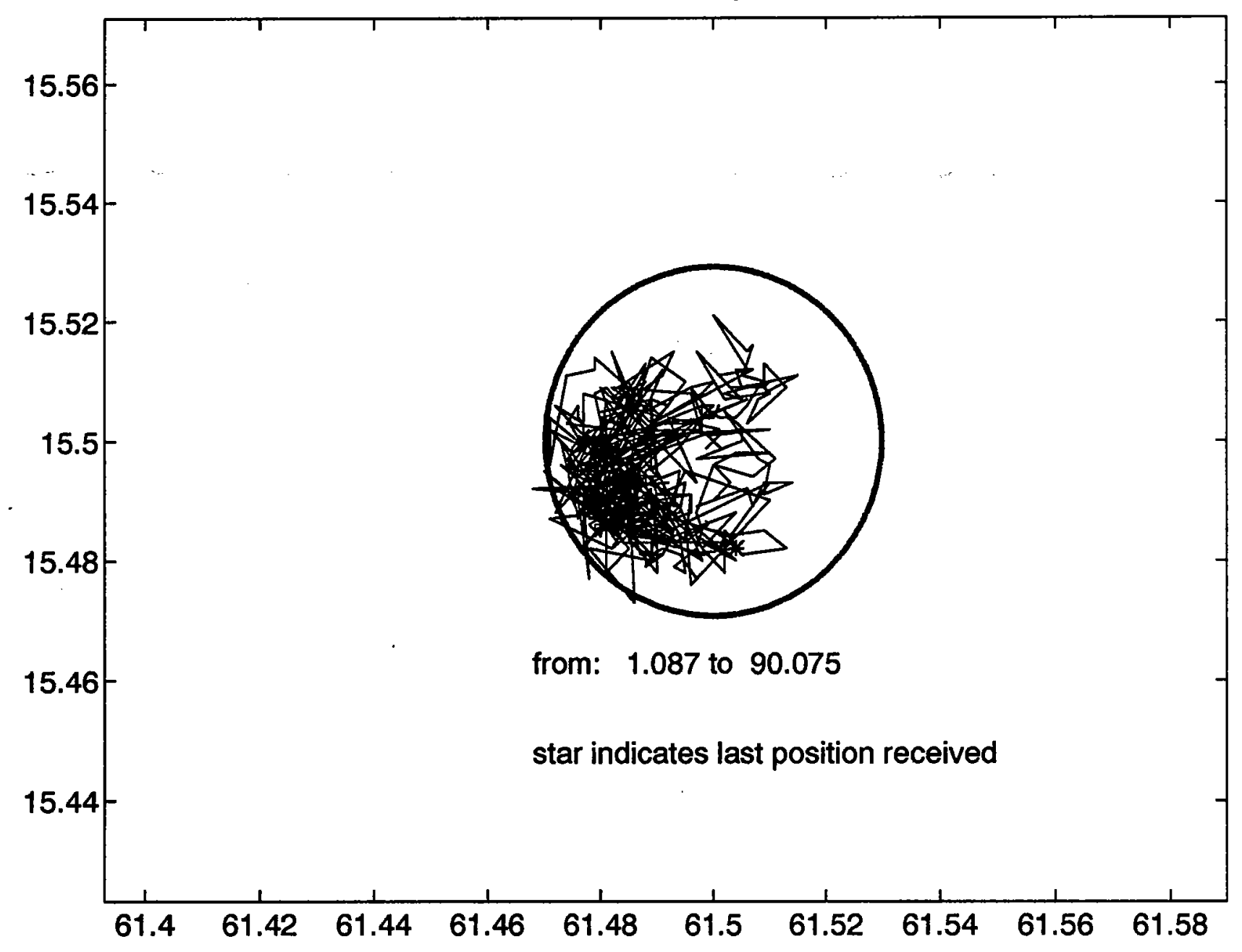




\section{Acknowledgements}

The author wishes to thank members of the Upper Ocean Processes Group for discussions and feedback during the development of the software. Discussions with N. Brink and A. Plueddemann during the preparation of this document are gratefully acknowledged. 


\section{DOCUMENT LIBRARY}

Distribution List for Technical Report Exchange - May 1995

University of California, San Diego

SIO Library 0175C

9500 Gilman Drive

La Jolla, CA 92093-0175

Hancock Library of Biology \& Oceanography

Alan Hancock Laboratory

University of Southern California

University Park

Los Angeles, CA 90089-0371

Gifts \& Exchanges

Library

Bedford Institute of Oceanography

P.O. Box 1006

Dartmouth, NS, B2Y 4A2, CANADA

Commander

International Ice Patrol

1082 Shennecossett Road

Groton, CT 06340-6095

NOAA/EDIS Miami Library Center

4301 Rickenbacker Causeway

Miami, FL 33149

Research Library

U.S. Army Corps of Engineers

Waterways Experiment Station

3909 Halls Ferry Road

Vicksburg, MS 39180-6199

Institute of Geophysics

University of Hawaii

Library Room 252

2525 Correa Road

Honolulu, HI 96822

Marine Resources Information Center

Building E38-320

MIT

Cambridge, MA 02139

Library

Lamont-Doherty Geological Observatory

Columbia University

Palisades, NY z10964

Library

Serials Department

Oregon State University

Corvallis, OR 97331

Pell Marine Science Library

University of Rhode Island

Narragansett Bay Campus

Narragansett, RI 02882
Working Collection

Texas A\&M University

Dept. of Oceanography

College Station, TX 77843

Fisheries-Oceanography Library

151 Oceanography Teaching Bldg.

University of Washington

Seattle, WA 98195

Library

R.S.M.A.S.

University of Miami

4600 Rickenbacker Causeway

Miami, FL 33149

Maury Oceanographic Library

Naval Oceanographic Office

Building 1003 South

1002 Balch Blvd.

Stennis Space Center, MS, 39522-5001

Library

Institute of Ocean Sciences

P.O. Box 6000

Sidney, B.C. V8L 4B2

CANADA

Library

Institute of Oceanographic Sciences

Deacon Laboratory

Wormley, Godalming

Surrey GU8 5UB

UNITED KINGDOM

The Librarian

CSIRO Marine Laboratories

G.P.O. Box 1538

Hobart, Tasmania

AUSTRALIA 7001

Library

Proudman Oceanographic Laboratory

Bidston Observatory

Birkenhead

Merseyside L43 7 RA

UNITED KINGDOM

IFREMER

Centre de Brest

Service Documentation - Publications

BP 7029280 PLOUZANE

FRANCE 


\begin{tabular}{|c|c|c|c|}
\hline $\begin{array}{l}\text { REPORT DOCUMENTATION } \\
\text { PAGE }\end{array}$ & 1. REPORT NO. WHOI-95-06 & $\begin{array}{ll}2 & \text { UOP-95-03 }\end{array}$ & 3. Recipient's Accession No. \\
\hline \multirow{2}{*}{\multicolumn{3}{|c|}{$\begin{array}{l}\text { 4. Title and Subtitle } \\
\text { A Processing System for Argos Meteorological Data }\end{array}$}} & $\begin{array}{l}\text { 5. Report Date } \\
\text { March } 1995\end{array}$ \\
\hline & & & a. \\
\hline \multicolumn{3}{|c|}{ 7. Author(s) Nancy R. Galbraith } & $\begin{array}{l}\text { 8. Performing Organization Rept. No. } \\
\text { WHOI-95-06 }\end{array}$ \\
\hline \multirow{2}{*}{\multicolumn{3}{|c|}{$\begin{array}{l}\text { 9. Performing Organization Name and Address } \\
\text { Woods Hole Oceanographic Institution } \\
\text { Woods Hole, Massachusetts } 02543\end{array}$}} & 10. Project/Task/Work Unit No. \\
\hline & & & $\begin{array}{l}\text { 11. Contract(C) or Grant(G) No. } \\
\text { (C) N00014-94-1-0161 } \\
\text { (G) }\end{array}$ \\
\hline \multirow{2}{*}{\multicolumn{2}{|c|}{$\begin{array}{l}\text { 12. Sponsoring Organization Name and Address } \\
\text { Office of Naval Research }\end{array}$}} & & $\begin{array}{l}\text { 13. Type of Report \& Period Covered } \\
\text { Technical Report }\end{array}$ \\
\hline & & & 14. \\
\hline
\end{tabular}

\section{Supplementary Notes}

This report should be cited as: Woods Hole Oceanog. Inst. Tech. Rept., WHOI-95-06.

16. Abstract (Limit: 200 words)

Upper Ocean Processes Group meteorological data is transmitted from surface buoys via Argos satellite and processed in an automatic mode on a UNIX workstation. Data is extracted from input files based on instrument type and experiment, processed as appropriate, and plotted, without user intervention. While the processing system normally runs automatically, it is designed so that modules can also be run directly from a terminal when necessary. The Argos processing system allows us to monitor the meteorological data being collected in the field, and provides early information about problems with sensors, instruments, or buoys, when they occur. The automatic process allows more information to be viewed with less effort, and increases the usefulness of the Argos data.

time-series data

UNIX software

b. Identifiers/Open-Ended Terms

c. COSATI Field/Group

Approved for public release; distribution unlimited.

\begin{tabular}{|l|l|}
\hline $\begin{array}{c}\text { 19. Security Class (This Report) } \\
\text { UNCLASSIFIED }\end{array}$ & $\begin{array}{l}\text { 21. No. of Pages } \\
60\end{array}$ \\
\hline 20. Security Class (This Page) & 22. Price \\
\hline & $\begin{array}{l}\text { OPTIONAL FORM 272 (4-77) } \\
\text { (Formerly NTIS-35) } \\
\text { Department of Commerce }\end{array}$ \\
\hline
\end{tabular}

